\title{
Analysis of the West Virginia Child Abuse and Neglect 2005 Court Improvement Program's re-evaluation
}

\author{
Kathryn Alexandra Rood \\ West Virginia University
}

Follow this and additional works at: https://researchrepository.wvu.edu/etd

\section{Recommended Citation}

Rood, Kathryn Alexandra, "Analysis of the West Virginia Child Abuse and Neglect 2005 Court Improvement Program's re-evaluation" (2006). Graduate Theses, Dissertations, and Problem Reports. 745.

https://researchrepository.wvu.edu/etd/745

This Thesis is protected by copyright and/or related rights. It has been brought to you by the The Research Repository @ WVU with permission from the rights-holder(s). You are free to use this Thesis in any way that is permitted by the copyright and related rights legislation that applies to your use. For other uses you must obtain permission from the rights-holder(s) directly, unless additional rights are indicated by a Creative Commons license in the record and/ or on the work itself. This Thesis has been accepted for inclusion in WVU Graduate Theses, Dissertations, and Problem Reports collection by an authorized administrator of The Research Repository @ WVU. For more information, please contact researchrepository@mail.wvu.edu. 


\title{
Analysis of the West Virginia Child Abuse and Neglect 2005 Court Improvement Program's Re-evaluation
}

\author{
Kathryn Alexandra Rood \\ Thesis submitted to the \\ Eberly College of Arts and Sciences \\ At West Virginia University \\ in partial fulfillment of the requirements \\ for the degree of \\ Masters of Arts \\ In \\ Sociology
Approved by
Ronald Althouse, Ph.D, Committee Chairperson
Corey Colyer, Ph.D
James J. Nolan, Ph.D

Division of Sociology and Anthropology

Morgantown, West Virginia
2006

Keywords: Courtroom Organization, Child Abuse and Neglect, Court Improvement program, Institutions, Scapegoating and Reasonable Efforts Policy. 


\section{$\underline{\text { Abstract }}$ \\ Analysis of the West Virginia Child Abuse and Neglect 2005 Court Improvement Program’s Re-evaluation}

\section{Kathryn Alexandra Rood}

This is a secondary Analysis of the West Virginia Child Abuse and Neglect Circuit Courtroom system based on the 1995 and 2005 Court Improvement Programs State Evaluations. This article focuses on the West Virginia child abuse and neglect court in relation to Reasonable Efforts Policy. The Evaluations gathered responses from the Judges, Prosecutors and Caseworkers. We reviewed the responses using Jacob and Eisenstein's courtroom workgroup model. Our analysis reveals that policy as an ideal and in practice enacts power over the courtroom workgroups ability to comply with federal standards. These standards and policy requirements create tension and precedence for an uneven power hierarchy in the courtroom workgroup. The Court Improvement Program has not looked at their interview responses from a sociological perspective until this essay. 


\section{Dedication}

This research would and could not have happened without the guidance and support of Dr. Ronald Althouse, Mary Anne Rood, Richard Rood, Justin Rood, Jon Rood, Robert Gratton and my fellow Graduate Students. Thank you all for your advice and patience through adversity. This document and any good that comes from it are for you. 


\section{Table of Contents}

\section{Chapter 1: Introduction}

The Child Abuse and Neglect Context in West Virginia........................................................... 3

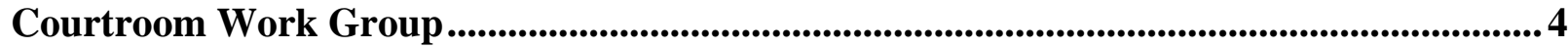

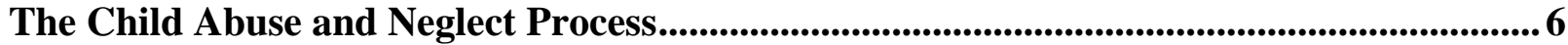

CIP Assessment and Re-Assessment Process ...................................................................... 7

Chapter 2: Background Significance

Evolution of Child Abuse and Neglect Policy ..................................................................99

Court Improvement Program in West Virginia ..............................................................11

West Virginia CIP Assessment and Re-Assessment Process ............................................112

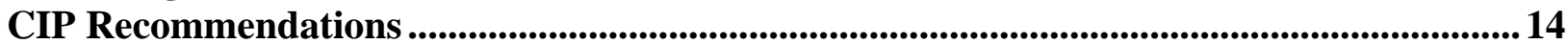

Courtroom Workgroup Organization and Theory ............................................................ 15

Stages of the West Virginia Child Abuse and Neglect Process ................................................20

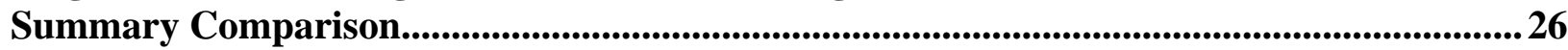

\section{Chapter 3: Methods}

My Study: A Secondary Analysis of the CIP Interviews.....................................................227

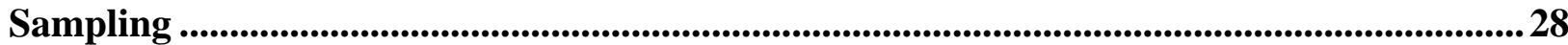

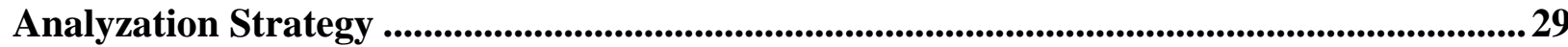

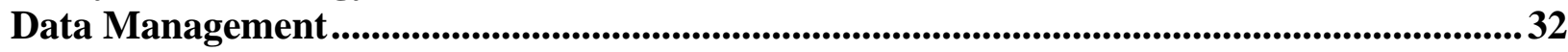

Limitations of the Study ....................................................................................................... 33

Chapter 4: “Reasonable Efforts” Ideology or Practice

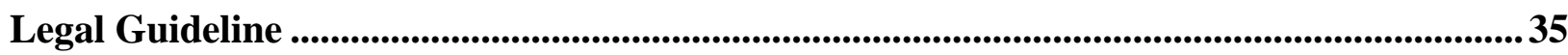

The Practice of "Reasonable Efforts" ................................................................................................ 36

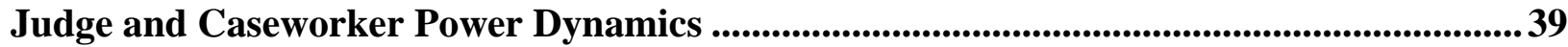

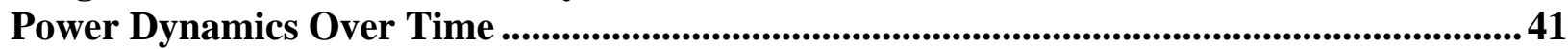

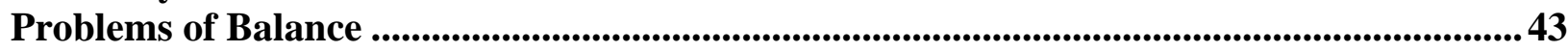

Chapter 5: DHHR Caseworker's Role

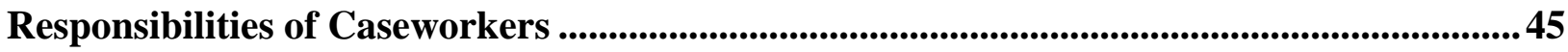

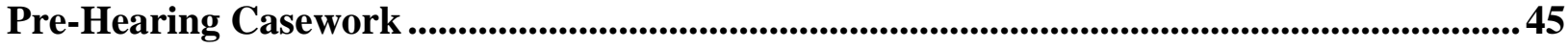




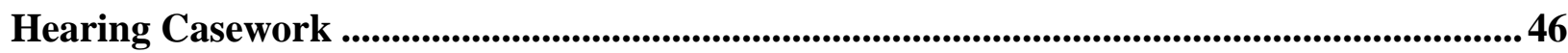

Post-Hearing Casework ................................................................................................................................ 49

Chapter 6: The Courtroom Workgroup in the Child Abuse \& Neglect Court

Workgroup Roles ..................................................................................................................................... 51

Status Hierarchy …………......................................................................................................................... 53

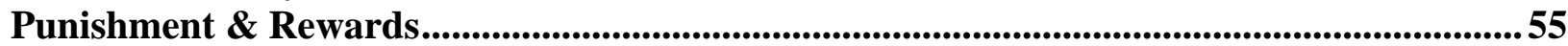

Chapter 7: Conclusions \& Recommendations

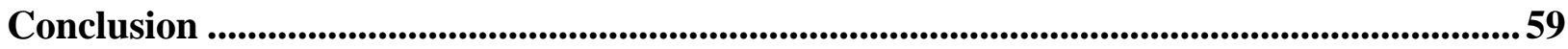

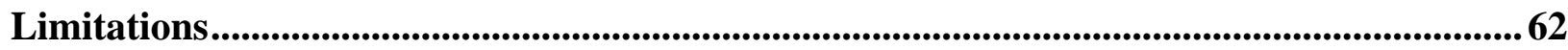

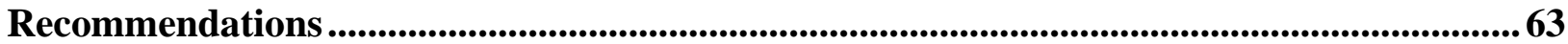

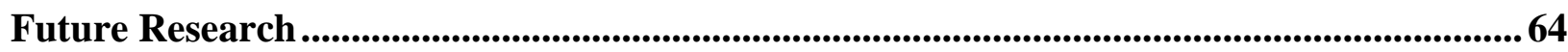

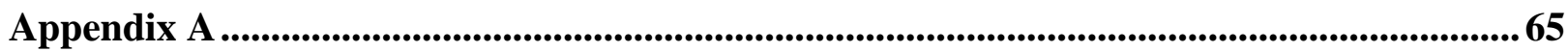

Appendix B ...................................................................................................................................66

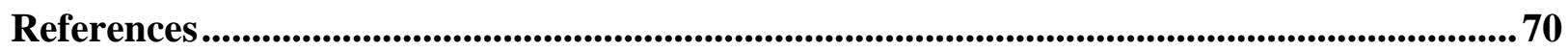




\section{Chapter 1: Introduction}

The Court Improvement Program (CIP) evaluated the West Virginia’s child abuse and neglect Circuit Court in 1995 and 2005. This federal programs goal was to provide States the means to assess their child abuse and neglect proceedings. States were encouraged to process a case in a 12-month period and if they did this successfully they were rewarded with adoption and foster care matching funds. In both assessments, West Virginia failed to meet the minimum mandatory requirements for "Reasonable Efforts” policy funding.

This funding supplies 3 to 1 matching funds (Title IV-E funds) to the Department of Health and Human Resource's (DHHR) foster care and adoption services. In order for these funds to be granted to the Department, the court must enter a "reasonable efforts" policy determination order within 60 days of a child's removal. The two assessments illustrate that the court has either not submitted these orders or the child abuse and neglect cases have extended past the governments 12-month time period. For the past ten years this funding has not been granted to DHHR.

Among the individuals that were evaluated in the CIP assessments were the judges, prosecutors and DHHR caseworkers. These individuals make up the core West Virginia child abuse and neglect court; that is, the core "courtroom workgroup." Their interactions and group role dependency is what powers the Court. The previous assessments have not addressed this courtroom workgroup dynamic. Within this court workgroup, the caseworker's role is most essential. The caseworker's are the one's that originally investigate abuse claims, file the petition, and provide the other courtroom members with the reports that comprise the information for the child abuse and neglect court cases. 
When DHHR is deprived of funding they can no longer provide adequate care to children and their families. Since the Court is dependant on the Department, and the Department depends on the courts judicial process, "reasonable efforts" policy creates a means for checks and balances within the workgroup. Only the Court can order the funding that must be furnished to DHHR. This funding allows caseworkers to continue services to families around the State and for caseworkers to alert the court to abuse and neglect situations. If funded, then the children that are caught up in this system will have better care which will allow caseworkers to expedite the child abuse and neglect hearing process.

Lack of funding has created a fiscal strain that may deprive DHHR of enough qualified caseworkers (that can afford to work in the Department). This fiscal strain in turn, may over tax the remaining caseworkers or may affect the department's capacity to fulfill their obligations in the State's child abuse and neglect Circuit Courts. When the Department is unable to create quality reports the judges and prosecutors are unable to efficiently and expediently conduct child abuse and neglect cases. This cyclical phenomenon may continue to compound with each passing case and year.

Over the past ten years the child abuse and neglect Circuit Court has improved their overall compliance rate with the Federal CIP standards by $10 \%$ from the time of the original 1995 assessment. During 1995-2005 the number of cases went from 647 to 1,744; more than doubling in ten years. The past assessments have offered recommendations such as judicial, prosecutor, and caseworker training and court order generating software (JANIS) but have missed opportunities to address the child abuse and neglect court from a sociological perspective.

This research attempts to bridge the gap between administrative policy ideology and the reality of "reasonable efforts" policy that drives practice. I will illustrate the caseworker's role 
as a guide by employing information gathered from previously unused open-ended interviews from both 1995 and 2005 CIP assessments. In order to understand how the abuse and neglect court is a sociological institution, we want to address how the "reasonable efforts" policy determines and provides structure for DHHR's role in the child abuse and neglect court.

\section{The Child Abuse and Neglect Context in West Virginia}

In the past eleven years, policies regarding child protection laws have been shifting from focus on the immediate safety of a child toward a wider focus on children's continued welfare and family reunification. The policies have increased the responsibilities of child protective agencies through family preservation models that encourage safety, welfare, case management and permanency (Court Improvement Program Re-Assessment 2005, Pg.1). These policy changes have coincided with an annual increase in the rate of new abuse and neglect fillings in West Virginia. According to the court improvement program, in 1994 the annual number of child abuse and neglect filings was at 647 cases and ten years later in 2004 the number of cases had risen to 1,744 annual filings (Court Improvement Program Re-Assessment 2005, Pg1).

West Virginia launched a child abuse and neglect circuit court improvement assessment in 1994 through the Federal State Court Improvement Program. This program enabled states to gain funding to evaluate their child abuse and neglect proceedings. Such information was meant to augment or restructure the state child abuse and neglect circuit courts. The West Virginia Supreme Court of Appeals used results from the 1995 report to institute new periods for proceedings and to create court order generating software. These steps were meant to enrich and strengthen the states child abuse courts. After a ten-year period, the child abuse and neglect circuit courts were re-assessed by the Court Improvement Program. By and large, the 2005 
assessment illustrated that the courts had advanced, however the pace of change fell short of the mark.

The Federal government's criterion was that States should have $75 \%$ of their child abuse and neglect cases achieve final placement status within a twelve-month time frame. "This time frame was established to cut down on the number of children languishing in the system (Knepper \& Barton 1997, 291).” In 1994, West Virginia had a compliance rate of $44.8 \%$ and (when the State was re-evaluated) in 2004, the compliance rate had risen to 54.9\%. This change although a positive achievement, failed to meet the Federal time criterion.

The State’s Court Improvement Oversight Board (CIOB) published its 2005 report (based on the 2004 study) that includes recommendations that relate to training and administrative orders. The perspective that the State's improvement program has used is largely focused on administrative policy and turns to employing “accounting” software to address problems in the process. The point of this analysis is to look at the structure and processes of the court workgroup in an attempt to understand the interactions and social networks that inundate the West Virginia child abuse and neglect circuit courts organization. The State's improvement program focuses on maximizing permanent placements through policy and software that generates court orders using preformatted templates, but does not address human agency.

\section{Courtroom Work Group}

The administrative policy that drives the "everyday" functioning of the child abuse and neglect courts is called "reasonable efforts" policy. This policy states that DHHR and the court make "reasonable" attempts to prevent a child from being removed from its family. The removal 
of a child is often how abuse and neglect proceedings begin. It is in this way that the initial step of the abuse proceedings is attached to "reasonable efforts" policy.

DHHR assigns caseworkers to every child abuse and neglect case around the State. These caseworkers are responsible for the investigation of abuse or neglect prior to the initiation of the process. DHHR presents their findings to a County Prosecutor, who in turn brings a petition (the petition outlines the abuse or neglect charges) to the Circuit Judge. The judge looks at the petition and calls the judicial process to order.

The judges, prosecutors and DHHR caseworkers, comprise the core workgroup that adjudicates child abuse and neglect cases. These are the professionals that work together on a daily bases to ensure that children who have been abused or neglected are safe and if possible reunited with their families. Therefore, they are referred to as the courtroom workgroup.

CIP reports have anchored administrative changes to child protective policy which were intended to correct or expedite the process. If, however, the core members of the child abuse and neglect circuit court are not involved in the process, then their unique perspective will be lost. Without such understanding administrative policies may not be as effective as intended. The courtroom workgroup constitutes the workers that perpetuate the child abuse and neglect process.

The courts and affiliated agencies are expected to enhance their roles as fact finders to incorporate administrative elements of oversight and reflectivity into the system. Previously, their opinions had not been given an opportunity to provide a deeper understanding of the social interactions between workgroup members in the process. This exploratory analysis attempts to identify and analyze the child abuse and neglect circuit courtroom workgroup (Judges, prosecutors and DHHR caseworkers) perspectives. 
The courtroom workgroup members have a working network, which allows them to process and collect individuals into socially acceptable groups or families in the broader contexts of our society. This description of "family" may (sound unsympathetic) but in child abuse and neglect courts the family is an ever changing arrangement or commodity. Discussing the child abuse and neglect workgroup separates the family-group from the workgroup or rather the content from the form. It will provide a more dimensionalized image of the child abuse and neglect system; thus such analysis seeks to advance the system by understanding the interactions that have been a part of the courtroom setting.

\section{The Child Abuse and Neglect Process}

Administrative rules and policies dictate the format of each phase of every hearing. There are five basic phases in child abuse cases: filing of the petition, the preliminary hearing, an adjudication hearing, the dispositional hearing, and the permanency review hearing. Three of these phases are driven by specified improvement periods, which allow the families the ability to interact with the allegedly abused or neglected child in a controlled environment. Improvement periods are conducted under supervised conditions to enact the improvement or come to a recognized conclusion. The administratively dictated time allotted for a child abuse case is twelve months. If an Improvement Period is granted, child abuse and neglect cases can last well over fourteen months or longer. It is rare for a child abuse and neglect case to be conducted without any improvement periods, it usually only occurs in emergencies (like sexual abuse). As a fail safe measure Multidisciplinary Treatment Teams (MDT) are formed for the purpose of negotiating the services appropriate to each child abuse and neglect case. The MDT's are formed at the end of the petition filing and work consecutively along side the hearings and 
generally take place outside of the court. Below is a diagram of the child abuse and neglect system.

Table 1: West Virginia Child Abuse and Neglect Circuit Court Procedural Timeline.

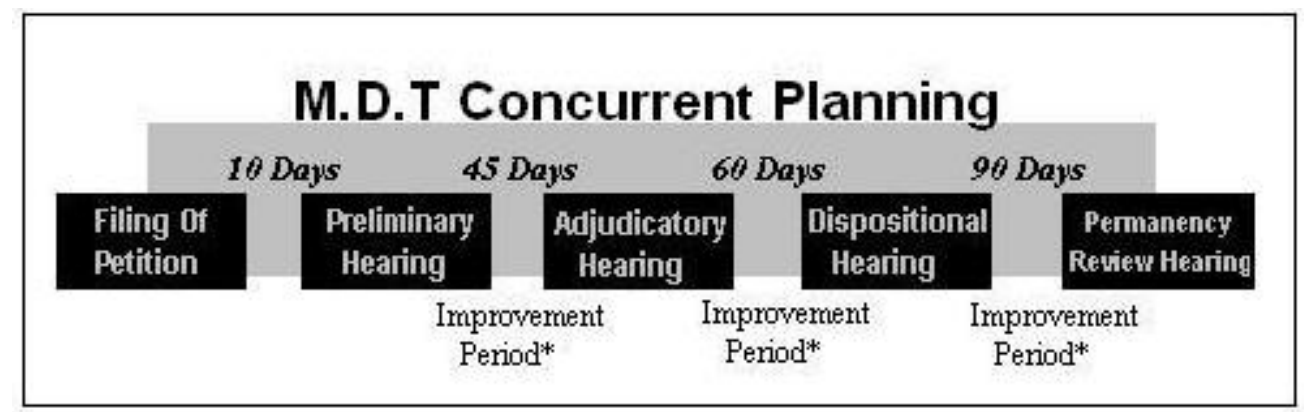

* Improvement Periods are generally conducted in 90-day intervals, with possible extension periods of 3 to 6 months.

To assure that the judges, prosecutors, attorneys and caseworkers are processing cases quickly enough; policy such as "reasonable efforts" policy is established to motivate the court. The court must make an official finding (under the "reasonable efforts" policy) that states that the court and the DHHR have reasonably attempted to reunite family and child. If the court does not enter this finding, then DHHR is disallowed funds to continue foster care programs or adoption proceedings for that child. We propose that the threat of this persuades the courtroom workgroup to work together to allow the child abuse and neglect process to be negotiated forward, while appearing to flow smoothly. However, this administrative pressure does not take into account the everyday dynamics that the courtroom workgroup professionals experience.

\section{CIP Assessment and Re-Assessment Process}

The Court Improvement Programs evaluations were comprised of questions that assess the child abuse and neglect system from both a political and an administrative viewpoint. Each assessment, the 1995 assessment and the 2005 re-assessment, used both open and close-ended questions in mailed survey and the face to face interviews. The information that the CIP report 
used was from the close-ended items, which answered what was asked, but did not address "why" the workgroup answered the way they did. The open-ended interviews were gathered but not analyzed. The interview information as well as open-ended comments to questionnaire items was left for future research because court improvement reporting had relied on ordinal level measurements. The unused open-ended responses promised an opportunity to gain understanding of the system from perspectives closer to those of its members, rather than ordinal measures of success and changes which depicted the perspective of the administered court. The open-ended interview responses provide a much-needed "why" to the close-ended quantitative reports. They provide voices from the perspectives of the courtroom workers who act as the gears that propel the child abuse and neglect circuit court system forward. The West Virginia child abuse and neglect Circuit Court systems have not been examined from a sociological perspective. This perspective focuses on the professional groups and their dynamics (interactions). These dynamics are navigated by the workgroup through administrative policies and Federal mandates. 


\section{Chapter 2: Background Significance}

In this chapter, I undertake discussion in greater depth of the policy and processes, workgroup organization and roles of the West Virginia child abuse and neglect law. First, I discuss the precedents for child abuse and neglect "reasonable efforts" and "contrary-to-welfare" policy. Next, we examine the origin of the CIP, West Virginia’s involvement with CIP, the CIP assessment and Re-Assessment process. In the last section I deal with the professional roles and the courtroom workgroup.

\section{Evolution of Child Abuse and Neglect Policy}

During the 1980’s the United States government began to focus on issues regarding children, families, neglect and abuse. Spousal abuse and child neglect gained significant public attention after an emergency room medical report stated that eight out of ten children that were brought to the emergency room, suffered from child abuse (Child Welfare Information Gateway, 2006). This report aroused the public to be more interested in domestic violence issues, as well as, child abuse and neglect. The previous policy stance on child abuse was to remove the child from the home, and place the child in foster care, and then move on to the next child in need. This would, ideally, take the child out of danger and quickly relocate the child to what the government assumed would be a better environment.

As public attention to child abuse grew, questions about the adequacy of solutions offered by the current system also became more critically focused. Fearing the current child abuse and neglect system would fall under further public scrutiny Congress decided the child abuse and neglect system was flawed. Congressional wisdom argued that children were placed in foster 
care for years, needlessly removed from families and would inevitably grow up in the foster care system without ever having a permanent, stable family environment. Confronted, Congress was prompted to enact the Adoption Assistance and Child Welfare Act (AACWA) of 1980 or Public Law 96-272 (Knepper \& Barton 1997, Pg. 290).

This law shifted attention to family preservation instead of a process of removal, placement, docket continuation and case closure. The law stated, "Permanent homes prepared children better for life as productive adults (Knepper \& Barton 1997, 290).” It mandated that child welfare agencies had to submit plans that described the family preservation services and actions taken by the Department of Health and Human Resources (DHHR) office to maintain family unification.

The AACWA of 1980 was paired with the Social Security Act to facilitate a policy process of federally required child abuse and neglect findings of "reasonable efforts" and “contrary-to welfare.” Without these standards, the DHHR looses valuable federal funds which assist state foster care and adoption agencies. "Reasonable efforts" are findings stating that the Department of Health and Human Resources, in conjunction with the court, made a reasonable number of attempts to prevent a child from being removed from its family. The term “Reasonable,” means that DHHR tried to keep the family together prior to the child's removal.

“Contrary-to-Welfare” is a finding that establishes that staying at home is opposite (contrary) to the well being (welfare) of the child. "Reasonable efforts" and "contrary-towelfare” are determinations that exist in tandem and are considered inseparable. This set of policies form distinctive shaping elements in the child abuse and neglect courts. They allow administrative (government) outsiders (lawmakers) to monitor the child abuse and neglect system and levy penalties on the court based on the courtroom workgroup's ability to further the 
docket.

These findings became known as "reasonable efforts" and they made the DHHR in conjunction with the Circuit Courts responsible for determining whether "reasonable efforts” had been made before a child was removed from a home. The act held the courts responsible for assessing whether the Department of Health and Human Resources made "reasonable efforts;” in other words, that the court or an administrative review panel must, first of all, hold hearings within 18 months of a child's removal in order to determine permanent placement and second, that the administrative review panel or court must review a child's foster care status every six months. This status check was used to ensure compliance with the family case plan which propels a case forward, while at the same time dictating that processes attempt to reach family reunification.

\section{Court Improvement Program in West Virginia}

Towards the end of the 1980’s Congress suggested an improvement initiative that would evaluate and grant additional federal funds to states that sought to address the problems confronting abuse and neglect circuit courts. A few years later, in the early 1990's, the State Court Improvement Program (CIP) was launched by the federal government. The CIP provided states with the necessary funds to assess and address problems within the abuse and neglect court systems. States began applying to the CIP initiative slowly, but by 1993 almost all of the states in the country were involved.

The incentive for states to take part in the CIP was that participation ensured matching funds for the adoption and foster care services. Each state's child abuse and neglect courts had to meet a mandatory compliance rate within a set period for a state to receive matching funds. 
The match funding from this congressional initiative is called Title IV-E funding. The State would have to file a report showing that "reasonable efforts" were made to reunite the families as well as having seventy-five percent of all child abuse and neglect cases to reach final disposition (within a twelve month period) in order to receive Title IV-E funds. Apart from providing funding, the Court Improvement Program gave states a chance to assess the amount of dysfunction within their courts and address the issues confronting the circuit courts.

West Virginia was one of the first states to take part in the CIP in 1993. The Court Improvement Oversight Board’s (CIOB) job was to conduct the initial assessment run by the state’s CIP. By 1995, the state had successfully completed its primary evaluation and steps were taken to improve the dismal circuit court compliance rates. The original state CIP assessment found West Virginia met the federal guidelines for minimum compliance at a rate of 44.8 percent (Court Administrative Office, Pending Case Age/County Summary Report, 1995.)

This means that in 44.8 percent of all child abuse and neglect proceedings within West Virginia in 1995 complied with the federal guidelines. This percentage fell 30.2 percent shy of the 75 percent federal standard. This meant that 58.2 percent of child abuse cases were not being handled in the allotted period and that the State would not receive Title IV-E funds. The CIOB generated a series of recommendations to be implemented after the assessment was completed.

\section{West Virginia CIP Assessment and Re-Assessment Process}

Armed with this knowledge, the West Virginia Supreme Court of Appeals through the leadership of the CIOB ordered training programs for their Judges, Prosecutors, Department of Health and Human Resources (DHHR) caseworkers, Attorneys, and Court Appointed Special Advocate (CASA) volunteers. This training provided the officers of the court with a valuable, 
comprehensive and equivalent context for approaching future adjudication of child abuse and neglect cases. Software inspired by the 1995 CIP evaluation was introduced to expedite the court order writing process, the software was called JANIS (Juvenile Abuse and Neglect Information System). It was actually introduced during the 1995 CIP process. It contained preformatted orders that required case specific elements to be entered into a pre-formatted form that generated a full report that was thoroughly and appropriately composed.

This technical advance was meant to alleviate the time and amount of paper work required for a proper court order to be filed. Training, technology, and court ordered state policies would take a certain amount of time to be fully instituted. It was with this understanding the CIOB proposed an implementation period of ten years to ensure ample time for the court to facilitate the alterations and evolve.

Ten years later in 2005 a re-assessment of the child abuse and neglect process in Circuit Courts was then conducted. The re-assessment used the same three information-gathering techniques as the previous assessment but focused on three of the original five court districts. The previous study had focused on seven counties. It was ascertained through a careful assessment of past data that the same geographical and jurisdictional information could be gathered using four focal counties within three districts.

The focal districts selected were the $7^{\text {th }}$ Circuit Logan County that had a two judge single county circuit, $11^{\text {th }}$ Circuit Greenbrier and Pocahontas Counties with a two judge multi-county circuits, and $17^{\text {th }}$ Circuit Monongalia County that had a two judge circuit (Court Improvement Program Re-assessment 2005, pg. 49). These three circuits ran the gambit of geographical regions in West Virginia including urban and rural populations within multi-county and singlecounty circuits. This provided data that was used to represent the statewide structure. It was 
also the most efficient, temporally and financially.

\section{CIP Recommendations}

Analysis of the results of the 2005 West Virginia child abuse and neglect Circuit Court Improvement Re-assessment made it clear that technical and administrative changes had not produced the necessary 30.2 percentage point raise in compliance rate. In comparison to the original 1995 assessment the state's overall compliance had risen ten percent in a decade. This raised West Virginia's compliance to 54.9 percent and lowers the federal compliance gap from

30.2 percent to 20.1 percent. This change is encouraging, but in order to close the gap the State re-endorsed its procedures and again suggested training (same as the 1995 assessment) be offered to Judges, Prosecutors, Attorneys, DHHR caseworkers and CASA volunteers to better prepare them for representing abused children.

It was recommended that appropriate training be instilled for the special software program JANIS throughout the State. Since the courts paper work in 1995 was rarely found properly filed or completed. The software allowed child abuse and neglect court reports to be filed more efficiently and similarly in the counties that had employed the software. Although the state strongly encourages the use of JANIS, it simply is not applied in all of the counties.

The CIOB (Court Improvement Oversight Board) in conjunction with West Virginia University’s Survey Research Center conducted both the 1995 and 2005 CIP assessments. The CIOB took the results in the original assessment and re-assessment in report form to the West Virginia State Supreme Court of Appeals. The new report was based on the findings from the reassessment. At the end of the report, there was a list of recommendations that were almost identical to the 1995 CIP assessments comments. Both assessments emphasized more training 
for court workgroup members (judges, prosecutors and CPS workers) and the promotion of the JANIS software.

The past recommendations have enhanced the court workgroup member's common knowledge about abuse and neglect cases. It is true that child abuse and neglect courts have improved their compliance rates, but it is also clear that the improvement has come in the form of a trickle instead of the wave of change proposed for the system. It is my belief that greater success can be realized through understanding the courtroom workgroups (judges, prosecutors and CPS caseworkers) daily dynamics.

\section{Courtroom Workgroup Organization}

Several terms and concepts need to be explained starting with the term courtroom workgroup and the concept of the West Virginia child abuse and neglect circuit court process. The courtroom workgroup is a collection of roles and obligations that comprise a courtroom within a judicial system's jurisdiction. This child abuse and neglect courtroom workgroup generates all judicial activity appropriate to the court process, and is comprised of judges,

prosecutors, and caseworkers. The courtroom workgroup relationship is structured by the legal statutes but what we are interested in understanding are the roles and obligations embedded in the comments of the courtroom workgroup members.

The circuit court in West Virginia is comprised of several members or officers of the court. The parties that regularly comprise the cast and crew of the child abuse and neglect courts in West Virginia are Judges, Attorneys (child and adult/respondent), Prosecutors, DHHR Caseworkers and in some circuits Court Appointed Special Advocates (CASA) volunteers. Their professional relationships and workgroup interactions (or dynamics) comprise the 
mechanism of the child abuse and neglect judicial system.

In an effort to focus on the principle courtroom actors this study will not examine the CASA volunteers, the Attorneys, or the Parents and Children being processed. The CASA volunteers are an important resource for the court and the child abuse and neglect professionals, but CASA is a newer program and has not yet been adopted in all of the State's child abuse and neglect circuit court jurisdictions. Only 17 districts have had CASA's. It was also not a part of the 1995 CIP assessment. Research based on the affect of CASA or Representative Attorneys in the child abuse and neglect courts will be left to future researchers when more data is available.

The children and families who are the client's of child abuse and neglect court cases are assumed to exert case specific influences on the court's workgroup dynamic and are a constantly changing collection. Due to the variability of the families, children, and content of their cases, they are not attached to my working definition of the courtroom workgroup. Their changing dynamic is not measured by the CIP; so, it must be delegated to future research. The individuals that comprise the courtroom workgroup are the Judges, Prosecutors and DHHR caseworkers from the 1995 and 2005 CIP assessments.

Courtroom workgroup members have specific guidelines that enable them to accomplish their roles in the judicial process. How these individuals carry out their roles varies in correspondence with their ideal courtroom duties and their responsibilities in practice. It is understood that they are all members of the child abuse and neglect judicial process that thrives on continuing its work, if not daily interactions between courtroom workgroup members. However what has not been explained are the relationships, the power/status embedded in these roles and responsibilities and obligations that each of the professions represent. To understand this element of the courtroom workgroup, the CIP responses were used to express each of the 
group's role perspectives, their perspectives on the other professions roles, and perceptions of power and status expectations within the child abuse and neglect court. The West Virginia child abuse and neglect court process includes array of players, each of whom perceives his/her role in the system with a varied degree of importance that is often influenced by policy. These connections form collective bonds and are organized through formal (administrative policy) and informal (perspectives) dynamics. These dynamics include expectations of what doctrines to uphold within each profession and the forms of behavior accepted among the courtroom workgroup, as a whole.

The concept of an organized courtroom workgroup was first developed by Herbert Jacobs and James Eisenstein analysis of the felony justice system entitled "The Felony Justice System: Courtroom Organization" in 1977. Their work defines the courtroom as an organization with informal rules (not detailed in the State Code) that allow the workers to negotiate cases rather than forcing them into constant conflict. Although the felony courts and civil courts are different entities, they share the same need for cooperation between professionals. In this way the worker's producing the courtroom workgroup may vary, but the professional groups are limited to the confines of jurisdiction. Conversely, members of the courtroom workgroup will meet more than once and must work together.

In order to test and apply the theory, it had to be broken down into separate concepts that can be re-assembled to explain the courtroom workgroup organization. David Neubauer's analysis deconstructed and separated the workgroup organization in to five composite parts: shared decision making, shared norms, socialization, sticks and carrots (my notion of "rewards and punishments") and goal modification. Each of these elements is imperative for a courtroom workgroup model to function. These elements represent the relations expressed in the dealings 
between the individuals in the workgroup, the inter-reliance of the group members, and the general methods and regulations that a courtroom workgroup uses to perpetuate its self.

These five elements are taken from an article that discusses courtroom workgroup organizational theory in relation to child abuse and neglect courts in order; "to understand how workgroup dynamics affect policy (Knepper \& Barton 1977, Pg. 288).” Paul E. Knepper and Shannon M. Barton's article on “The effect of courtroom dynamics on child maltreatment proceedings" provides an insight into how the child abuse and neglect court system in Kentucky could apply a courtroom organizational model to its child abuse and neglect system. Knepper and Barton reanalyzed Kentucky's initial CIP assessment in terms of the courtroom workgroup model. The five processes were shared decision making, shared norms, socialization, sticks and carrots (punishment and rewards), and goal modification. Using these processes created by David Neubauer allow us to make Jacobs and Eisenstein's model analytically useful (Knepper \&Barton 1997, Pg. 294).

Armed with these analytical resources Knepper and Barton reviewed the CIP statewide assessment surveys, and showed that Neubauer's processes formed in Kentucky's child abuse and neglect courts matched the courtroom workgroup organizational model that Jacob’s and Eisenstein had created. The study makes a case to demonstrate that the courtroom work group can be related to child abuse and neglect circuit courts.

Knepper and Barton's article shares a common model, subject matter, and location with our West Virginia research, but my work differs in the way court policy is used. It looks at how "reasonable efforts" policy shapes the child abuse and neglect courtroom workgroups interactions. This difference is based on the hypothesis that policy has a shaping influence on courtroom workgroups interactions and can be used as a tool to further understand the courtroom 
workgroup as an organization.

Each member of a courtroom workgroup has his/her own specialized decision-making role; however, the group decisions are made in accordance with a set of informal work rules that the group has adopted (Knepper \& Barton 1997, Pg. 294). These informal rules can be understood by examining Neubauer’s five categories that represent a courtroom workgroup: shared decision making, shared norms, socialization, sticks and carrots, and goal modification. Shared decision-making allows the judge to be a formal leader in the workgroup while allowing blame for mistakes to be diffused. This may take the form of scapegoating one of the professional groups. Which judges are responsible for the overall progress of their court, they are not responsible for any glitches that occur outside of the courtroom. Outside the courtroom the prosecutors and caseworkers negotiate case plans for their clients (children and parents). By interacting in this way the professions can establish orders of precedence depending on location or role responsibility.

Shared norms are accepted codes of conduct or behaviors that the group deems to be appropriate. We can gather this information from comments that courtroom workgroup professionals make referring to the roles of other courtroom workgroup professionals or even the organizations goal. For instance, currently in child abuse and neglect courts, literally all courtroom workgroup members said that the safety of the child and reunification of families is their goal. Each of the workgroup professions has independent goals that coincide with the workgroups main goal. The judge wants to decide the case, the prosecutor wants to win the case and the caseworkers want the best result for the family and child. Shared norms can also be illustrated by statements that implicate a failure to fulfill responsibilities. This concept overlaps with all the other criteria for a workgroup organization because it concerns acceptable behavior, 
sanctions for misbehavior, and socialization under a common goal. All of these factors tie a workgroup together, bind them and express their organizational structure. These codes may vary depending on the courtroom workgroup; however, they all share the need to shelter the workgroup from strange or outside influences.

Socialization refers to the necessary phase of orientation or learning a workgroups structure (formal rules), informal rules and overall behavioral etiquettes. These criteria can be substantiated through the appearance of each of the other criteria. Socialization requires learning and for a group to work together they must learn to work towards similar goals. When a group, such as the child abuse and neglect workgroup, all individually of each other state the same goals it can be safely concluded that a socialization has taken place.

Sticks and carrots refer to rewards and punishments. They are the methods a workgroup uses to enforce group norms. One way that workgroups sanction members is through public demonishment or scapegoating. Knepper and Barton referred to this type of accepted courtroom workgroup behavior in the Kentucky child abuse and neglect courts. They said that protection of the courtroom workgroup was of the utmost importance and one way that the workgroup polices itself is through rewards and punishments.

These categories can be used to create an significant representation of the West Virginia child abuse and neglect circuit court that will enable administrators to understand the effect policy has on the system. This understanding can provide needed context and a partial account for West Virginia’s (WV) child abuse and neglect court's low Federal compliance rate.

\section{Stages of the West Virginia Child Abuse and Neglect Process}

The entire child abuse and neglect process is outlined in West Virginia Code Chapter 49 
and it specifies that, "The guiding purpose of child abuse and neglect laws is to provide a safe, stable, and permanent home for abused and neglected children (W. Va. Code 49-1-1).”

Essentially, the goal for the child abuse and neglect court is to achieve justice by providing a safe and stable permanent home for children adjudged as abused or neglected. With this goal at the center of the child abuse and neglect, court proceeding five procedural rules were created. Those rules stated that the court is expected to encourage the involvement of all community resource personnel and provide litigation, as well as representation to parties, while extending services to any party involved. (By any party we mean the children or parents that a child abuse and neglect case may revolve around).

Child abuse and neglect courts are to provide judicial oversight throughout the duration of case planning, to coordinate the decision making process, to provide a fair and timely case disposition, and to reduce any unnecessary delays in each cases management (Court Improvement Program Re-Assessment 2005, Pg. 2). The main proceedings are divided into five sections: 1) petition filing, 2) preliminary hearing, 3) adjudicatory hearing, 4) dispositional hearing, and 5) permanent placement review. Each of these phases has a strict time frame that the court must attempt to maintain.

\section{Petition Filing.}

A petition alleging abuse or neglect must be filed with the county circuit court to begin child abuse and neglect proceedings. (It is preferred if the complaint is from the county in which it is filed). Anyone can bring a petition forward; however, petitions are usually brought to prosecutors by CPS caseworkers. A petition must include the following to be served: it must specify the misconduct, give a description of the child or children, state what penalty or relief is sought, and a Uniform Child Custody Jurisdiction and Enforcement Act (UCCJEA) form should 
be attached (Court Improvement Program Re-Assessment 2005, Pg. 5). The court must immediately assign a preliminary hearing date when the petition is filed (W. Va. Code 49-6-1; Rule 20).

It is generally at this point that a child will be removed from the home. The DHHR caseworker will remove the child and then obtain a legal order from the judge that states that remaining in the home would be "contrary-to-welfare" of the child. Once this order is in Title IV-E funding can start to be received on a temporary bases. The court must then attempt to make a finding of "reasonable efforts" so the child's foster care or adoption assistance can continue to be funded by the federal and state governments.

According to West Virginia’s Code 49-6-2 (d), “Child abuse and neglect cases have priority over all civil proceedings, except for domestic violence proceedings and trials already in progress.” This is further emphasized by Rule 5, which essentially states that no case including criminal proceedings can delay a civil protection (child abuse and neglect or domestic violence) case. When the petition is served the respondents (children and parents) are assigned or offered counsel, a judge is appointed, and within 30 days of the petition being filed a Multidisciplinary Treatment Team (MDT) is formed (Rule 51). (See page 11, Table 1).

The MDT is comprised of the child’s parents, guardians, family members, the child if over 12 years of age, the child and the adult's attorneys, guardian ad litem, prosecutor or their designee, and any other individual that may be helpful to the treatment teams endeavor (Court Improvement Program Re-Assessment 2005, Pg. 11). Specifically, the MDT’s role is to provide the court with a recommended service plan before the disposition hearing that has assessed the situation, created a plan, and implemented the individualized case plan for the child/children involved (W.Va. Codes 49-5D-3 \& 49-5D-3(a) (3)). The MDT meetings are organized to meet 
separately but in conjunction with the court hearing phases that is, the petition filing, preliminary hearing, adjudicatory hearing, dispositional hearing and permanency review hearing.

\section{Preliminary Hearing.}

Ten days after the petition is filed and a court date is scheduled for the second phase of the child abuse and neglect court process. The second phase is the preliminary hearing and at this stage of the proceedings all parties are provided representation and the accusation of abuse or neglect is revealed. At this hearing, the court decides two aspects of the case; 1) where and with whom the child will reside, and 2) will the court order an improvement period for the parents or guardians. If the child is temporarily removed from the home, they can be remanded to the Department of Health and Human Resources or some responsible person (generally another family member).

Improvement periods can last for almost six months. A status conference must be held 60 to 90 days after the Improvement period is granted. The DHHR and the MDT at that time observe the family and create a family case plan that is turned in to the court. This conference awards families another attempt to rectify the abuse or neglect and reunite. If the family violates their case plan or relapses, the improvement period is over. Otherwise, at the end of the improvement period, before 60 days have passed the court must conduct a hearing to determine the final disposition of the case (Rule 38; Court Improvement Program Re-Assessment 2005, Pg. 12).

Family case plans are schedules that dictate improvement goals for a family by means of services that are made available to parents and children. Parents are expected to follow the case plans in order for the court to consider the return of the child. Case plans are generally created in Multidisciplinary Treatment Meetings (MDT) by the caseworker, attorneys, parents, prosecutor 
and anyone who has a direct influence on the child's life.

\section{Adjudicatory Hearing.}

After the termination of an improvement period and the preliminary hearing (if no improvement period was deemed appropriate) is the third court phase. The Adjudicatory hearing is similar to the preliminary hearing, although at the end of this hearing the court will either adjudged the child as abused or neglected, at the time of the petition filing or as a non-victimized party. After this judgment is passed, the child will either be returned to their parents or guardian or placed back into temporary placement with DHHR. If no improvement period is granted a dispositional hearing must be conducted within 45 days.

If an improvement period is granted, the dispositional hearing must be conducted 60 days after the end of the improvement period. If the child has been adjudged abused or neglected the DHHR must complete another child case plan that outlines where the child will be permanently placed and with whom (if reunification is not in the best interest of the child); what efforts were used by the department, suggestions for visitations, and the financial responsibility of the parents (Rule 28). The child case plan must be compiled in 30 days of the entry of the final adjudicatory order and it must be served to all parties at least 5 days before the disposition hearing (W. Va. Code 49-6-5(a); Rule 29).

\section{Dispositional Hearing.}

The fourth phase of the child abuse and neglect process has to be initiated under the same time constraints as the adjudicatory hearing, within 45 days if there is no improvement period and before 60 days have passed after the end of an improvement period ((Rule 32; W. Va. Code 49-6-12(k); Court Improvement Program Re-Assessment 2005, Pg. 19)). This fourth stage is the depositional hearing. At the dispositional hearing, the court makes its final verdict, which can 
vary as one of three basic outcomes. The child is adjudged abused or neglected, the court establishes an appropriate treatment, such as an additional improvement period and temporary placement for the child may be arranged or, the improvement period or periods have been deemed successful and the petition is dismissed. Other stipulations can be attached to these outcomes including referral of families to further agency services, terms for supervised visitations can be arranged, and parental right are terminated. The dispositional order must be entered into the court record before 10 days have passed and the order must contain the legal findings regarding abuse and "reasonable efforts" (Rule 36(a)).

\section{Permanency Review Hearing.}

The fifth and final phase is the permanent placement review that must be held every three months until permanency is achieved. In permanent placement reviews the courts continue to monitor the progress of the child pending permanent placement. A permanency hearing is expected to be held one year from the first finding of abuse or neglect (the first time the court judges a child to be abused or neglected) or 60 days after removal from the home if the department was not required to make "reasonable efforts" findings (this only occurs in emergency cases). The court prefers that a permanency hearing be held within 30 days of the disposition hearing although the official period is a year (Rule 36(a)).

The MDT's are in charge of reminding the Permanency Placement Review members of any future concerns regarding the child's placement. The permanency placement order must follow the same rigid 10-day time frame as the dispositional order. Rule 42(a). The order states whether permanent placement was achieved, through findings of fact and the conclusions of the law (2005 Court Improvement Program Re-Assessment.) Often if the court issues an order that confirms permanent placement has been obtained then the case is legally allowed to be dismissed 
from the court docket ((Rule 42(b), (c)). The court considers the case to have reached final disposition when a child is permanently placed.

These five phases incorporate the general format of the child abuse and neglect circuit courts (CANCC). Each phase is limited by a period and through legal decree; however, it is the core members of the courtroom workgroup that ensure expediently executed case dispositions. The courtroom workgroups interactions comprise the informal organizational element in this study. Their interactions are different from other professionals taking part in the judicial process for several reasons.

\section{Summary Comparison}

Child abuse and neglect court proceedings are not based on the same principles as criminal courts. Criminal court hearings are generally attempting to ascertain if the respondent actually perpetrated a crime. In child abuse and neglect courts an accusation of abuse or neglect is made, but the respondent is given improvement periods and offered services to address the problem. Fines are not given for abuse or neglect crimes. They may be attached if a respondent does not appear at court, but not for the abuse or neglect. No jury is used to decide the fate of a respondent; it is simply the ruling of the judge based on presented evidence. Fundamentally, the two court systems differ; the criminal court is attempting to punish, while the child abuse and neglect court is attempting to safeguard children and families. Child abuse and neglect courtroom workgroups try to negotiate their roles while achieving the modified group goal of final disposition and eventually furthering the docket. In this final way, criminal courts are similar to abuse and neglect courts both courtroom workgroups must work together, (to differing degrees) to achieve justice, perpetuate the process and, close cases. 


\section{Chapter 3: Methods}

\section{My Study: A Secondary Analysis of the CIP Interviews}

Starting in 1995 and 2005 the Survey Research Center (SRC) analyzed 62 interview questionnaires from judges, prosecutors and caseworkers in the state of West Virginia. These dates coincided with the Court Improvement Programs evaluation of the child abuse and neglect circuit courts. The responses I used came from 17 judges, 18 prosecutors and 27 caseworkers.

The interviews used structured questionnaires that were administered by attorneys, in both the years 2005 and 1995. Judges, prosecutors and caseworker's responses were written on the questionnaires during the interviews by attorneys. After the 2005 CIP re-assessment was submitted to the West Virginia Supreme Court of Appeals, the SRC gave me permission to use the interview questionnaires from both assessments. This data provided personal opinions from five focal Counties in the 1995 assessment and three focal Counties in the 2005 re-assessment. The three Counties from the 2005 assessment were among those in the 1995 evaluation and for continuities sake, are the Counties that I used for this research.

The data was given to the CIP oversight board, in an ordinal encoded format by the SRC to be compiled into assessment reports. The reports explained the legal interactive process that comprises the West Virginia child abuse and neglect Circuit Court System. After the 2005 report, both evaluations were compared and new recommendations for the courts improvement were suggested. The reports focused on the close-ended responses from the assessments (the mailed surveys), but did not incorporate the interview responses (that had also been collected). This means that the reports expressed ordinal response data but did not utilize the qualitative 
information that was gathered. The CIP structured interview responses came from questionnaires that were approved by the American Bar Association for use in the CIP's evaluations. These open-ended qualitative personally administered questionnaires are the documents used in this research.

\section{Sampling}

In the original assessment (in 1995) five jurisdictions were selected as demographically significant. They represented single judge and multi judge circuits, urban and rural areas, as well as multiple county and single county circuits. The SRC in conjunction with the CIP board choose to focus on three of the original five counties when the second assessment was conducted. The remaining counties still meet all of the same demographic requirements as those in the original assessment. The two counties that were removed from the focal unit did not affect the validity of these findings based on experiments run on the 1995 assessments data. The SRC found that if two counties were removed the same demographic information could be attained with no affect on the responses sentiments. The counties that were used in both assessments are Green Brier and Pocahontas Counties, Monongalia County, and Logan County.

The CIP re-assessment used a mixed method of mailed statewide surveys, personal interviews and case file reviews to gather data originally. The report was based on those three methods of data collection but the results were discussed from a policy perspective and focused on responses that could be categorized oridinally. There was no analysis of the social or human elements that comprised the process. The reports did not take into account the qualitative responses that were also collected in the evaluation processes.

The mailed survey data was entered into spreadsheets and the response frequencies were 
used to illustrate shortcomings in the system or more pointedly, with the courtroom workgroup (This was the same process that the CIP had used in 1995). Convenience sampling was used to obtain these structured interview responses from the West Virginia Survey Research Center (SRC). Most of the close-ended responses were used in the West Virginia Supreme Court of Appeals reports but the structured interview (open-ended) responses were not analyzed. The structured interview responses comprise the documents that our data is derived from.

\section{Analyzation Strategy}

Originally, the caseworker's responses were analyzed and separated by year, so that the construction of the West Virginia child abuse and neglect courtroom workgroup could be viewed over time. This gives the findings more depth and presents a more plausible and thorough representation of the courtroom workgroups usual interactions. Once the responses were separated and categorized by interview question number the responses were analyzed together. By separating the responses initially I was able to extract the consensus from each time period so that distinction between responses had a better chance of being revealed. Then once the responses were combined under the same interview questions a broader sense of the caseworkers, judges and, prosecutor's actual opinions and change through time could be recognized. Opinions from the judges and prosecutors were compiled using the same questions (unless otherwise noted). All of the questionnaires were created with similar themes although the questions that each profession answered were designed specifically for each profession.

This made it necessary for me to read through each of the questionnaires and pick out the main theme in each section of every form. In all of the interviews the most prevalent theme was “reasonable efforts” policy. The judges, prosecutors and caseworkers questionnaires were 
centrally based on evaluating the child abuse and neglect workgroup and each one was connected to the other through "reasonable efforts" policy questions. In these sections is where the data for this research was located. Several of the questions referring to "reasonable efforts" policy were the same in all of the workgroups questionnaires. These questions became the logical place for data to be collected.

The responses that were provided for these questions were direct and gave little indication about the workgroup, for the most part. Then two questions elicited unexpected responses from all three workgroup professions. The questions were answered but the responses included additional comments that did not always back up the respondent's initial statement. The two questions were:

1. "What, if anything, is the impact of the determination regarding reasonable efforts? Why?

2. "Describe your working relationship with CPS workers and any problems that occur in this relationship?”

The responses that courtroom workgroup members furnished were in some cases rambling and other cases defensive. This type of fracture in the responses is where the deeper wealth of interaction knowledge was gained.

An example is that one respondent specified that they were always fair to the caseworker. This response was freely given in regards to their relationship to the caseworker and even though the question had no element of accusation within its formation the respondent deemed it necessary to express their egalitarianism. Another respondent's response started by mentioning past caseworkers then compared them to new caseworkers and went on to conclude that none of the caseworkers could help being overwhelmed. The interview question did not assign blame or 
suggest that there was any type of failure that was provided completely by the respondent. Neither of the questions asked for a comparison and the questions were not making any accusations. Responses like these caused my attention to focus on the relationship between the caseworkers and the rest of the courtroom workgroup. Furthermore, since all of these questions were asked under the auspice of “reasonable efforts” policy it seemed that perhaps this policy could serve as a window into the power structure of the child abuse and neglect courtroom workgroup.

Through the analysis, it became apparent that most of the "reasonable efforts” policy questions focused on the caseworkers. The caseworkers were referred to more than the prosecutors and the judges on the questionnaires and in the three professions separate responses. I assumed that judges and prosecutors should be more closely connected to "reasonable efforts" policy, since they filled more prestigious or accountable positions according to the law. I researched "reasonable efforts" policy in an attempt to understand the workgroup. Conversely this gave me a chance to determine why caseworkers were being directly connected with “reasonable efforts” policy.

"Reasonable efforts" policy states that the court and caseworkers have a joint role in the policy determination. DHHR is responsible for assisting the child and family while the court is responsible for providing insight as well as taking an objective view; by assessing that “reasonable efforts” policy has been enacted. These determinations have direct influence on DHHR foster care and adoption funding and an indirect influence on the court. Reasonable efforts” policy relates to the court by granting the judge and prosecutor the ability to penalize or reward caseworkers. This makes the balance of power within the workgroup unequal compared to the role responsibilities of each of the courtroom workgroup members. 
The focus of this research is to understand the ideals behind "reasonable efforts" policy, how it is operationalized, what affects this operationalization has on the judges, prosecutors and caseworker's status, funding and overall workgroup dynamic. This investigation can provide an image of the West Virginia child abuse and neglect circuit court as a symbiotic workgroup whose policies have distinct affects on the workgroups ability to meet Federal Compliance rates.

\section{Data Management}

When I received the questionnaires they were in an inconsistent format. Some of the responses were typed and other responses were written out by hand. In order for the data to be more consistent and reliable I transcribed it and put it into a similar format for analysis. This allowed the material to be analyzed separately as well as combined for a more thorough look at the Court.

This transcription and reformatting phase coincided with my open coding process (Strauss 2003, Pg 27). The open coding process allowed me to look for key reoccurring elements, like power, status and role. These three elements became my primary coding groups. During the second phase of coding the concept of ownership became inseparably linked to all three of the primary coding elements. The responses were then compiled into three main transcripts: 1995 and 2005 CIP DHHR Caseworkers Responses, 1995 and 2005 CIP Prosecutors Responses, and 1995 and 2005 CIP Judges Responses. Organizing the responses in this manner made them easier to comprehend and code.

The responses were originally coded by focal county. There were three focal counties used in both the 2005 assessment and the 1995 evaluation. Each of the three different counties were coded by lighter ink colors if they were from the 2005 re-assessment and black ink if the 
responses were from the 1995 original assessment. This was done in order for me to note any similarities in the responses over a decade. The original assessment contained responses from twelve judges, twelve prosecutors and twenty caseworkers. The 2005 assessment had responses from five prosecutors, six judges and seven caseworkers.

The sample for this study is comprised of judges, prosecutors and, DHHR caseworkers. All of whom were polled by the Survey Research Center in conjunction with the CIP. The responses of each of these groups were recorded and then divided into categories based on their profession. The professions were each assigned a color of ink and all the responses were placed next to each other. The theme of power linked to role was key in understanding the workgroups structure. Through this coding phase I realized that caseworkers were being assigned the most responsibility for "reasonable efforts" policies.

Each of the workgroup's perspectives were separately gathered and organized. Then the courtroom workgroup responses, where placed together, to create a representation of the professional courtroom workgroups power dynamics based on their responses. A status role association became apparent through the lens of "reasonable efforts" policies and the words of courtroom workgroup members. These responses and their imagery begin to express internal relationship conflicts between professions. When I went back through the responses and pulled out quotes that related to my main topics; each of these coding elements refocused my analysis of the open-ended responses.

\section{Limitations of the Study}

This study has several limitations. The first limitation comes from the limited size and nature of the responses. The open-ended interviews conducted by the CIP were taken from the 
focal Counties. These Counties were supposed to be representative of the demographics of West Virginia, but the number of responses from the 2005 interviews was noticeably less. Originally the entire states child abuse and neglect circuit court workgroup members were surveyed, however only a fraction of them were interviewed. The responses were written down by the interviewing attorneys. This means that the responses are not verbatim, but close interpretations. This made searching for invivo terms communality, all but impossible. Another limitation in this study was the questionnaire. The questionnaires construction varied depending on which profession the interviewee was apart. Each group’s questionnaire was slightly different. The judge questionnaire might contain questions that the other two questionnaires did not. Questions might be arranged in separate formats or be altered in such a way that the question was no longer asking the same question that it was in other questionnaires. To minimize the damage that these varied formats could cause I choose to examine sections that were present in all three questionnaires. Consistency and validity were salvaged through the use of two questions that appeared with the same wording in all three questionnaires. Since my lens was "reasonable efforts” policy and the questions were the same despite the separate formats the data that this study came from can be considered consistent and valid. 


\section{Chapter 4: "Reasonable Efforts” Ideology or Practice}

"Reasonable efforts” policy refers to the joint role caseworkers and the court have to ensure that a child and their family are given assistance prior to the child being removed. According to the Social Security Act (SSA) sections 470-479a, Title IV-E (foster care and adoption funding) “directly rely(s) on court activity,” since “...the basis for the child being in foster care must be a court order that finds that placement would be in the best interests of the child (See Appendix B).” The original removal can be temporarily covered by a court order or a voluntary placement agreement filed by a DHHR caseworker. However, after 180 days that order is no longer sufficient and a "reasonable efforts" determination order must be submitted, by the court.

\section{Legal Guideline}

The original court orders or voluntary placement orders must be filed in the County or jurisdiction of the child's residence by the caseworker within 24 hours of removal. The 180-day permit from the court is not intended to last that entire time, because section 472(a) (1) of the Social Security Act (SSA) states that:

"When a child is removed from his or her home, a case specific judicial determination whether reasonable efforts were made to prevent removal or that reasonable efforts were not required must be made within 60 days of the removal of the child from his or her home (See Appendix B).”

This means that the policy of "reasonable efforts" requires that within 60 days of removal, whether the voluntary placement or court order provides more time or not a judicial 
determination of "reasonable efforts" must be entered. This order cuts the courts leeway between the provisional order and submission of the "reasonable efforts" order from 180 days to 60 days. This puts the court at a slight time deficit at the very beginning of the child abuse and neglect proceedings. This deficit makes DHHR active caseworkers as well as the judges make fast-paced decisions, and when one member (let alone two) of the courtroom workgroup is hurried, they all have to match pace.

This rushed pace starts the courtroom workgroup at a run and creates strain between the groups. The judge, caseworker, and prosecutor are all linked to strict guidelines regarding “reasonable efforts” policy and the child abuse and neglect formal process (See Table 1, Pg. 9). These avenues are rigidly set in law and the only place for this strain to give is through the courtroom workgroups interactions.

This is not the direct intent of policy setters but it is a consequence of making policies before understanding the dynamics of a workgroup. The ideology of "reasonable efforts" is based in the administration's goal for child abuse and neglect Courts. That goal is the reunification and therefore preservation of families whenever reunification is not harmful to the child. When this goal is extended to the courtroom workgroup it is operationalized by becoming two of three modified goals that workgroup must attain for each case to be considered a success. The three goals that the courtroom workgroup is driven by are: 1). the safety of the child, 2). reunification or preservation of family if possible and, 3). furthering the docket (through which the court perpetuates itself).

\section{The Practice of "Reasonable Efforts"}

The child abuse and neglect courts are attempting to successfully hear each abuse and 
neglect case that comes through but "reasonable efforts" policy attaches DHHR foster care funding to court orders. This court order adds a new step in the courtroom workgroups dynamic while simultaneously imposing a twelve-month period to encapsulate the entire process which puts pressure on DHHR to deliver valuable information to the court. With this added bracket "Reasonable efforts" policy strain starts to influence the way DHHR relates to or at least thinks of "reasonable efforts" policy which changes their self-assigned role in the courtroom workgroup.

The caseworkers were asked, "What, if anything, is the impact of the determination regarding reasonable efforts? Why? the caseworker's interpretations and responses were divided. The caseworkers all answered the question but focused on "reasonable efforts" policy impacts differently. Part of the responding caseworkers emphasized the financial and literal results of "reasonable efforts" policy determinations; while the other caseworker's interpretation focused on the value, responsibility, and ownership of "reasonable efforts" policy determinations in child abuse and neglect cases. One caseworker said "When (reasonable efforts) findings are made, foster care funding is available. So it is important that the reasonable efforts findings are made (CIP: DHHR Interview, 1995).” Another stated that “(Reasonable efforts) Moves cases along (and) gets us funding (CIP: DHHR Interview, 2005).”

These are examples that represent the literal and financial focus reflected by the CPS caseworkers. They express the impact of "reasonable efforts" policy as a part of the process the courtroom workgroup uses in order to manage a case. For these caseworkers "reasonable efforts" policies are a means to an end. The policies supply funding which provides for the children involved in the system and helps to perpetuate the system by supplying caseworkers that furthering the docket. 
An underlying element in these responses is that "reasonable efforts" policy determinations are not the responsibility of any one courtroom workgroup profession. These responses treat the impact of "reasonable efforts" policy as a common issue. Neither of the responses assigned ownership (responsibility) of "reasonable efforts" policy. The caseworkers did not make any claims that focus on the judges, prosecutors or caseworkers.

In the other interpretation caseworkers ascribed ownership of "reasonable efforts" policy determinations. A caseworker expresses that the policy determinations are a reflective measure for caseworkers to evaluate their performance and the professions ideals. One respondent stated:

“The determination of reasonable efforts has a huge impact. If the department hasn't made reasonable efforts, the department has not done its job. CPS's job is not to take kids away from their parents, but to preserve families (CIP: DHHR Interview, 1995).”

This response blatantly expounds the ideological goal of the child abuse and neglect court, while assigning "reasonable efforts" policy to the caseworkers as an evaluation tool. When she says that the department has not done its job the respondent is using "reasonable efforts" policy as an evaluation tool. Stating that without the determination the caseworker has not done their job. She then chastises the caseworker or other caseworkers by explaining their job to them. The manner in which she does this is important.

She explains the unit for measurement and then provides an ideal of the child abuse and neglect system by means of a common assumption about caseworkers. The assumption is that caseworker's first role is to take children away; it is a secret fear of all parents. That is certainly a role that a caseworker can and in extreme cases does fulfill, but generally caseworkers work with families several times before they result to removal of a child. The use of a stereotype adds a level of credence to her point of view for fellow caseworkers because they are aware of this stigma assigned to caseworkers by outsiders. 
A different caseworker shared some of the same opinions regarding "reasonable efforts" value as a device which measures the competency of caseworkers. This other respondent takes a more severe approach to the impact of reasonable efforts. The other caseworker responded:

"No reasonable efforts means the department is not doing its job; which means a loss of funding, loss of services (to families), possibility of losing position and federal grants become lost funding (CIP: DHHR Interview, 2005).”

This response aggressively attaches penalties to caseworkers from simply not doing their job and losing their position to loss of agency funds which would result eventually to the loss of jobs for other caseworkers. Moreover the response resembles a scare tactic to keep other caseworkers in line. By stating that if "reasonable efforts" policies are not met a chain of damaging events will take place attributes a deep responsibility to caseworkers. That for the DHHR system to function and for the courts goal to be realized the caseworker must make sure that "reasonable efforts" policy determinations are made or the repercussions are the caseworkers fault.

\section{Judge and Caseworker Power Dynamics}

When part of the caseworkers are convinced that "reasonable efforts" policy is their role to uphold and the other half sees "reasonable efforts" policy as a means to an ends. There is a lot of room for manipulation (intentional or unintentional) and when part of a group is already accepting the responsibility for a determination it is natural to allow that group to continue feeling as if they are responsible for that policy. This exact situation can be observed from a comment made by another caseworker. He stated:

"Funding from the federal government could be affected if reasonable efforts are not determined. This gives the Judge a chance to see if the department was doing their job (CIP: DHHR Interview, 1995).” 
In this response the caseworker gave the judge power to wield "reasonable efforts" policy as an evaluation tool over DHHR. The caseworker explains that since funding is tied to "reasonable efforts" policy the judge can use this policy as a control for caseworkers. In this situation the judge is afforded a higher status than the caseworker because they have the ability to reward or punish the caseworkers with "reasonable efforts" policy. A reward would be the judge allowing the Department to get funding and a punishment would be to deprive them of funding.

Nowhere in the courts goal, operationalization of the courts goal or, in the definition of "reasonable efforts" policy does it state that this policy is for evaluation purposes. This is from one response by a caseworker, so it could be a rough opinion except that judges were asked this same question independently of the caseworkers and they came to the same conclusion. That "reasonable efforts" policy is an evaluation tool to be used by the judge to assess the caseworkers but also to use in order to uphold the goals of the court. The 1995 judge's opinions can be summarized by one quote. A judge exclaimed:

"A reasonable efforts determination makes sure that the department is performing up to its responsibilities. The determination helps make sure the family unit is not dissolved or kept apart longer than it should be. This determination is made because the one goal is to keep the family unit intact. However, the goal is not to keep the family intact if unity is not in the best interest of the child or if the child is in danger. The primary goal is to get the child in permanent placement whether that placement is with the parents, adoption, or permanent foster care. Another goal is to prevent the child from being moved from one place to another (CIP: Judge Interview, 1995).”

This response shows that the child judge attaches the consequences of "reasonable efforts" determinations firmly with caseworkers. He refers to "reasonable efforts" policy as a way to assess the Department. The judge goes on to outline the ideals of the child abuse and neglect workgroup. As he is discussing the ideals he intones that "reasonable efforts" policy 
makes sure that families are not kept apart needlessly.

The only individuals that could keep a family apart and also have "reasonable efforts" as an evolution tool would be the caseworkers. In these first two lines of the judge's response, he claims control of evaluating the Department and backs up the common stereotype of caseworkers. That they are going to take children away from their families given the opportunity. Then he asserts that the goal is not to prevent family reunification so long as the child is in not serious harm. He ends his response by stating that the child's permanent placement is the ultimate goal; successfully taking all of the focus away from the caseworkers after reinforcing his status.

The Judges further specify that; "The determination of reasonable efforts is made to get federal funds (CIP: Judge Interview, 1995).” What they do not say is that the federal funds derived from "reasonable efforts" determinations are the match-funds that DHHR's foster care and adoption programs need to function. By doing this the judges are establishing the "reasonable efforts" policy and flatly placing that duty in the hands of DHHR while securing their place as the party necessary to determine the policy. Judges are needed to make a decision and file the appropriate paperwork however, they are not granted the ability to evaluate the caseworkers with "reasonable efforts" policies.

\section{Power Dynamics Over Time}

Ten-years later during the re-assessment in 2005 the judges made similar comments with very similar themes. One respondent simply stated that the impact of "reasonable efforts" “Creates accountability in the Department activities (CIP: Judge Interview, 2005).” This statement mirrors the idea that the Department should be kept on their toes, as well as supports 
negative public opinions about caseworkers. One other judge stated that the impact of “reasonable efforts” should be more idealistic:

"Regarding the impact (of reasonable efforts). I feel the impact more is for the funding issues and even more impact on the individual case. The "reasonable efforts" language is not as important to the Court as pursuing the best interest of the child. The "reasonable effort determination" is something that is done primarily because the Supreme Court says to do it; but the issue should not be reimbursement of DHHR, but whether the child is being properly served (CIP: Judge Interview, 2005.”

The judge admits that the impact is about funding, but explains that Department reimbursement should not be the rationale for making the determination. By making this specification he intones that "reasonable efforts" policy is a funding concern that can get in the way of the ideal goal of the court. The goal is to protect children and place them in permanent stable homes.

Funding however, has a way of modifying groups goals and in the child abuse and neglect Circuit Courts of West Virginia “reasonable efforts” policy does just that. The purpose of the child abuse and neglect court in this state is to protect children while giving families every opportunity to reunify. Policies like “reasonable efforts” have a tendency to reshape the emphasis of an institution.

The courtroom workgroup generally has its own set of modified goals, one of the goals is to attempt to reunify families and protect children, but its other two driving goals are to meet the policy requirements (on state and federal levels) and to efficiently progress the docket. Advancing the docket keeps the courtroom workgroup running and ensures that the court is reaching as many people as possible. It also means that the workgroup is doing their job since most statistics on courts are taken in reference to the number of cases that are completed divided by the total number of cases and, child abuse cases are no different.

A valuable point that the judge brought up is compounded by the fact that "reasonable 
efforts” determinations are not based solely on DHHR, but also on the courts efforts. Other than the court issuing an order that "reasonable efforts" policy determinations have been made it is difficult to monitor whether the court is upholding its responsibility to "reasonable efforts." This indicates that every time the department fails to provide "reasonable efforts" the court receives fall out from the administrative sanctions placed on DHHR. Loss of funding (reimbursement) for the Department could mean a loss of caseworkers due to budget cuts or an inability for the court and Department to address the needs of abused or neglected children and their families.

One final dynamic came from the judge’s responses to the "reasonable efforts” impact question. The dynamic is the reliance on its self that the courtroom workgroup needs in order to function. Robert M. Emerson once said:

"Just as one may look at the ways in which individuals present and defend desired images of self, so one may look at what have been called "presentational strategies" employed by institutions to create and maintain desired impressions of their ongoing activity (Emerson 1969, Pg.172).”

What Emerson coins "presentational strategies," we refer to as the concept of "shared decision making.”

The judge is the overseeing authority in child abuse and neglect cases, however they depend on the information gathered by the DHHR and presented through a legal intermediary (the prosecutor) in order for the judge to attain the necessary information. This exact process is the courtroom workgroup concept of "shared decision-making." Shared decision-making is beneficial to the judge because they can remain an informal leader and if an issue arises, blame can be diffused. 


\section{Problems of Balance}

Policies directed at both the court and caseworkers do not evaluate "reasonable efforts" policy or the (75\%, twelve month) Federal compliance rate. Neither policy stipulates that the court or DHHR has the ability to use "reasonable efforts” policy as evaluation tools. Each of these policies does relate to DHHR foster care funding but they are not required for the process to continue. They are simply funds; funds that are needed so that DHHR can provide services to safe guard the child and possibly reunite the family. The services help the child abuse and neglect court hearing process work smoother by providing informal negotiations of services. These negotiations save the court time during the formal hearings. The self-assignment done by some of DHHR through “reasonable efforts” policy brings up the question; "What is DHHR's role?” If it is not to be evaluated by funding policies, what do the caseworkers add to the courtroom workgroup. In the following chapter we are going to examine the role of DHHR and how their role is inter-related to the other workgroup members; and represents the glue that holds the West Virginia child abuse and neglect courtroom workgroup together. 


\section{Chapter 5: DHHR Caseworker's Role}

\section{Responsibilities of Caseworkers}

This chapter will provide insight into the caseworker's role in the child abuse and neglect courts. It specifies the main three capacities caseworkers perform in any one case. I will show how "Reasonable efforts" policy and the strain of operationalizing this policy generates within the courtroom workgroup. This section also explores the resulting ownership of "reasonable efforts” by the court and DHHR. The final and most prevalent element in this chapter is the importance of caseworker's to the West Virginia child abuse and neglect process.

\section{Pre-Hearing Casework}

The West Virginia child abuse and neglect courtroom workgroup depends on three main members; the prosecutor, judge, and caseworker. The most vital of these courtroom workgroup members is the caseworker. While prosecutors and judges are ascribed higher statuses than caseworkers the caseworker is the most vital. They investigate child abuse and neglect allegations, work with children and families, provide services, create the petition, supply the courtroom workgroup with reports with updated case specific information and, find placement for abused and neglected children. The Department of Health and Human Resources consists of many different type of caseworker; the three roles taken by caseworkers in child abuse and neglect cases are investigator, active/CPS worker and, placement worker.

A caseworker is responsible for the facilitation of the court process. A caseworker initially investigates allegations of abuse and neglect. After the investigation, if the caseworker 
determines that staying in the home would be against the child's welfare the intake caseworker is expected to remove the child. These situations are considered emergencies and when a caseworker considers a child in danger they must remove that child. Once the child is safely removed from the home and put into temporary placement with a foster care facility; it is the caseworker’s duty to inform the local municipality of the removal (in emergencies).

\section{Hearing Casework}

When the child is removed, caseworkers are then responsible for drafting a petition that specifies the exact situation that prompted the child's removal. In most non-emergency action cases caseworkers have been working with families attempting to rectify abusive or neglectful situations. In these situations the caseworker has a chance to go to a prosecutor and suggest bringing a formal petition against a family prior to removal of the child or children.

From the moment, that the prosecutor accepts and submits the formal petition the child abuse and neglect courtroom workgroup begins to interact. According to West Virginia code Chapter 49, the preliminary hearing is scheduled for no more than 10 days after the child was removed. At this point DHHR's original investigatory intake-caseworker is delegated to the role of chief witness for the prosecution (who is representing DHHR) and an active caseworker (from DHHR) takes control of the case. The original caseworker is involved in the formal hearings and possibly the MDT meetings, but other than providing testimony they are no longer responsible for the child abuse or neglect case. This responsibility goes to an active, long-term, or CPS caseworker (these are all names for the same type of caseworker) who then takes the lead position for DHHR.

The active caseworker’s role is contingent on, “... ii) providing, directing or coordinating 
appropriate and timely delivery of services to any child suspected or known to be abused or neglected (and services to the child's family); iii) initiating appropriate legal proceedings (Court Improvement Program Re-Assessment 2005, Pg. 27).”

These services are usually offered in concurrence with the legal hearing stages (MDT meetings) and intersect with the formal process during the improvement periods. Multidisciplinary treatment team meetings (MDT) are held by prosecutors and CPS caseworkers. They take place between each hearing to negotiate services for parents and children. MDT meetings are where case plans for families are created and discussed. Status reports are drafted by caseworkers during improvement period status meetings. The CPS caseworker's keep the judge and prosecutor abreast of the family and child's progress through status reports.

One aspect of this role is submitting documents such as: status reports, court summaries, the family and child's case plans as well as other progress reports. Family and child case plans outline the necessary services and changes that the Department considers imperative for the reunification of the family. In emergency cases where the child is in extreme danger the caseworker is not required to submit these reports to the court. However, in standard child abuse and neglect cases these reports are expected. A CPS caseworker in 1995 listed some of the reports that the department was responsible for in the following quote.

"The department submits the treatment plan (also, this is the case plan), protection plans (often attached to petition), previous treatment or case plans (as exhibits attached to the petition), psychological evaluations, monthly reports, monthly updates, and any other exhibit deemed important. All other parties get copies of these documents (CIP: DHHR Interview, 1995).”

This response demonstrates the wide scope of the reports that the CPS caseworker provides the court with from pre-trial (petition filing) until permanency is achieved.

The caseworker in this institution is an information broker; they transfer the information from observations and interactions into written documents, which confer the reports information 
to the courtroom workgroup. These documents ensure that all of the parties involved in the process receive the same information. When the courtroom workgroup has this information both the concurrent planning and formal hearings precede unimpeded to make clear and appropriate decisions.

The process of constant evaluation is only one aspect of the CPS caseworker's role. They are also expected to provide and coordinate the services that the children and their families need in order to be considered for reconciliation (reunification). Part of DHHR's service responsibility is eased by the MDT meetings these meetings allow qualified professionals in cooperation with the child's parents (and the child if age 12 or older) to rectify the deviant family dynamic.

Strategic planning occurs in MDT meetings. Caseworkers, prosecutors and relevant parties (parents, children, teachers, doctors, attorneys, etc.) can, during a meeting discuss the issues that surround the case without fear of a legal order that could stripe parental rights. The caseworkers role in MDT meetings is to record what the amassed "concerned” (relevant) parties conclude and send their conclusions to the judge (as well as the other parties involved in the case) (W.Va. Code 49-5D-3).

Improvement periods are similarly documented by the active caseworker as are the improvement period review meetings that the court is expected to conduct. These occur at the end of each improvement period. These meetings dictate whether an improvement period should receive an extension or not (See Table 1, Pg. 9).

The third role that caseworkers fulfill is witness to the prosecutor. In contrast the intakecaseworker and the active caseworker are expected to provide testimony during every formal hearing. The intake caseworker provides information about the incident that caused them to file 
the petition and the active caseworker provides testimony about the current state of services and the family’s progress. A caseworker from the original CIP assessment clearly demonstrates these roles when they stated:

"The intake worker did the initial investigation, filed the petition, took custody of kid and opened the long-term investigation. The intake worker testifies to all this along with testifying to the history, background, and the assessment of the case. The long-term worker will work with the family through the court process... (CIP: DHHR Interview, 1995).”

The CPS caseworker also answers any questions that the judge or prosecutor may have about the case (CIP: DHHR Interview, 2005). The testimony and reports that caseworkers file and provide are essential active ingredients in the child abuse and neglect courtroom workgroup. They justify the states rationale for convening the child abuse and neglect workgroup by providing the initial evidence.

\section{Post-Hearing Casework}

Up to this point, we have discussed two of the three types of casework done by caseworkers. The final type of casework occurs towards the end of the formal hearing process. When the dispositional hearing is conducted and the court decides the issues of placement and parental rights the caseworker's role shifts from preventative to permanent. This means that the caseworker stops attempting to reunify the family and instead tries to find foster care or another placement for the child.

These placement workers preside over the placement of the child for DHHR. Their role is to investigate the placement and compose the permanency review written reports. To be distributed to all of the other members of the workgroup. The permanency report contains a summary of effective or ineffective placements. These reports are used by all of the courtroom 
workgroup prior and during the permanency review hearing. A child's status in a home will be outlined and the parents and departments efforts will be included. The reports are the main resource for the judge. The information residing in the permanency report directly correlates to the judge's final determination.

At the permanency review hearing the foster care caseworker may be expected to testify and clarify any issues that the court may find unclear. The placement caseworker will assist in the acquisition of a child's placement whether that is with a relative, within the foster care system or through adoption (W.Va. Code 49). If permanent placement is not ordered it is the placement caseworkers job to continue to coordinate further court ordered DHHR provided services (such as visitation's between children and their biological families), monitor the progress, and send their reports back to the courtroom workgroup until the child is permanently placed.

Over the entire course of the West Virginia child abuse and neglect Circuit Court process the caseworkers investigate the root abuse or neglect, submitting the courts founding petition, coordinating the services, communicating the case specific detail, distributing the information to the entirety of the group, and aid in the child placement process. Caseworkers have a plethora of obligations and several different caseworkers per case tangibly complete the child abuse and neglect system. The intake-caseworker, active or CPS caseworker, and the placement caseworker are all fulfilling the duties that are expected of DHHR. Since all of these different caseworker's are a part of the same profession they comprise the concept of child abuse and neglect caseworker. 


\section{Chapter 6: The Courtroom Workgroup in the Child Abuse \& Neglect Court}

\section{Workgroup Roles}

This chapter focuses on combining "reasonable efforts" ideology and practice with the courtroom workgroup. The courtroom workgroup is comprised of three member's judges, prosecutors, and caseworkers. The judges and prosecutors roles begin with the filing of a Petition and end with the Permanency Review. In contrast, the caseworkers start the initial investigation of a family for child abuse or neglect and work through and past the Permanency Review.

They do this to ensure safety as well as stability of the child and in an attempt to reunify the family. Caseworkers are also the most directly affected member of the courtroom workgroup when "reasonable efforts” policy determinations are made. In this chapter we are going to explore the way that "reasonable efforts" policy determinations structure caseworkers perceived roles in the West Virginia child abuse and neglect Circuit courtroom workgroup institution.

In order for this discussion to continue the courtroom workgroup’s individual roles have to be defined. The roles are characterized in a status hierarchy based on the status attributed to each of the workgroups by the other courtroom workgroup members. The Judge is assigned the highest status in child abuse and neglect court while the caseworker's occupy the lowest status position. The judge in the child abuse and neglect Circuit Court process is solely responsible for making decisions in the five stage system. The stages are: 1) petition filing, 2) preliminary hearing, 3) adjudication hearing, 4) dispositional hearing and 5) permanency review hearing. The judge is a parental figure in the workgroup he or she oversees the courts functions 
(See Table: 1, Appendix A). Judges make final decisions in each phase and determine if “reasonable efforts” occurred. It is not the judge’s responsibility to work with the concurrent planning sections that occur outside the courtroom. All of the negotiation occurs in planning section. The caseworkers and the prosecutors work together as the navigators in the planning meetings. Caseworkers use case plans to list expected services and prosecutors serve as their legal representative. The prosecutor and caseworker use concurrent planning and MDT meetings as informal meetings to steer the progress of child abuse and neglect cases.

The judge acts in an oversight capacity for the court while the prosecutor acts as intermediary and delegate to the court. They represent the state and the caseworker. The prosecutor's role is to present the departments position and act as the attorney for the state.

The prosecutor initially tells the caseworkers if the case meets legal requirements before the petition is submitted to the court. The standard protocol is that DHHR does the investigation on abuse or neglect charges and then takes their findings to the prosecutor. The prosecutors act in an initially advocatory position for DHHR before the petition is filed and as a legal state representative in court during the formal hearings. They provide advice and representation to the caseworkers. This action gives the prosecutor their second status as the department's legal State counsel (intermediary and delegate).

The judges make authoritative decisions at the designated formal hearings and use the Departments reports to oversee the total legal process as it evolves from petition to permanency. Their responsibilities include: bringing the petition to the courts attention, investigating the alleged misdeed, providing as well as coordinating appropriate services to children and their families, when necessary to remove the child or children, be responsible for the child's custody and, the safe placement of the removed child. These are the responsibilities set forth by the West 
Virginia code Chapters 49-2-1 and 49-6A-9.

The caseworker builds the courts case and is then responsible for services and making reasonable efforts to keep families unified and children safe. The judge presides over the formal stages of adjudication and the prosecutor represents the caseworker's position for the state. These roles in association with the courts status hierarchy texture the courts context.

\section{Status Hierarchy}

When the prosecutors were asked, "Describe your working relationship with CPS workers and any problems that occur in this relationship?” The prosecutors stated that their working relationship ranged between good and tolerable but they often added unflattering commentaries about caseworkers. These statements often characterized caseworkers as incompetent, over worked and lazy. An example of this attitude comes from a prosecutor who exclaimed:

"I believe I've reached an agreement with the office. It's a stormy relationship. On occasion, our office was totally unable to support their position. I have at all times put them on the stand and let them tell the court their position. I have never prevented them from telling their side (CIP: Prosecutor Interview, 1995).”

The important element of this quote to focus on is where the respondent changes his comments from describing his work relationship to protecting his position. This occurs when he says: "I have at all times put them on the stand and let them tell the court their position. I have never prevented them from telling their side (CIP: Prosecutor Interview, 1995).” The prosecutor did not specify any problems directly however, his sudden topic switch signifies a great deal of conflict. The prosecutor does not give any introduction or segway to any problems and in fact an interviewer might have assumed that the past differences of opinions might have been the 
problem he's had with caseworkers. Apparently, at some point he felt the need to protect himself against some element in his relationship with caseworkers. This unexpected statement demonstrates that there is some type of conflict present between the prosecutor and caseworkers.

This response provides a useful example of status at work. The prosecutor thinks nothing of explaining that he has reached an agreement with the department. This statement is important because he is assigning his opinion with the same value as the whole Department not just the caseworkers. He restates this element when he explains that the prosecutor's office did not support the position of the Department. Demonstrating that the office he is apart of has in the past had no good reason to support the caseworkers. The caseworkers are again, not mentioned even though the question clearly references the caseworkers, not the Agency. This suggests that the responding prosecutor sees the caseworkers and Agency as one entity. Lumping the DHHR and caseworkers as one makes their status much less complicated and have a shorter extent; where as the prosecutor is an individual and a part of a collective which gives him the power of an individual and the control of the prosecutors office.

Another prosecutor added to this opinion when he said:

"We have a good working relationship. The problem is that CPS workers are often not as familiar with the file as they should be or as he is. They don't prepare enough for hearings (CIP: Prosecutor Interview, 1995).”

This response adds another dimension to the prosecutor's opinions of caseworkers. He states that the caseworkers and he have a good relationship but, then he states that caseworkers do not know the case as well as he does. This is quite an accusation since the prosecutor is exposed to the cases information through the caseworkers. A comment of this nature illustrates that the prosecutor feels that the caseworker is not fulfilling their obligations to the court, the children or the families. The prosecutor adds that he is prepared for cases; this indicates that the weak links 
in the process or the group with the lowest status should be the caseworker. If the caseworker is unprepared then the prosecutor can not properly litigate the case. Still other prosecutors felt that she had:

"Generally a fairly good working relationship. Some CPS workers have ego problems and want to take every kid. Some are lazy. Some, however, are phenomenal. The prosecutor does not get to spend a lot of time with them. A whole new group of workers has come in, and she is not yet familiar with them (CIP: Prosecutor Interview, 1995).”

This response is a perfect example of the crossed signals that are cascading between the caseworkers and prosecutors. The prosecutors as the legal council of the caseworker have a slight status advantage, since their role is to litigate the caseworker position. If the prosecutor is at odds with the petition that the caseworker brings the prosecutor has the ability to not pursue the petition then the case does not reach court.

These quotes from the 1995 CIP assessment demonstrate that friction existed between the prosecutors and the caseworkers some of this can be accounted for by the lack of basic child abuse and neglect training for the prosecutor. Another contributing factor may very well be that the DHHR has some ownership to the petition when it is filed however once the court proceeding begins the court is given control of the case and the caseworker is relegated to another role. When this happens the courtroom workgroup members attempt to establish a power structure. The outcome of this is that the judge's role is to make decisions so he is assigned the highest status then, because the prosecutor speaks the language of the court they are given the next level of power and status, and then because the caseworker knows the case but is not a legal officer they are given the lowest status. 


\section{Punishment \& Rewards}

In essence, the courtroom workgroup is attempting to socialize and establish norms at the onset of each case. This can be verified by considering the concept of "punishments and rewards,” from Knepper and Barton which asserts “To be meaningful, group rules must be enforced (pg.294, 1997).” Rewards and punishments regulate the courtroom workgroup. Without regulatory alternatives the courtroom workgroup would have no mechanism shielding the group from non-workgroup members.

If norms are being followed rewards will be given, but when they are not sanctions or punishments are enacted. The prosecutors very clearly uphold this principle by carefully phrased public responses. Their responses depict control or state that the two groups have good relations; they then specify the problem with caseworkers.

The prosecutors were asked about problems with the "relationship” not with DHHR and at no point were they asked to evaluate the caseworkers. This practice in institutions tends to force a hierarchical structure that is present within the courtroom workgroup and creates occasional power struggles. This was expounded when a prosecutor explained that, "the prosecutor is only as good as the social worker (CIP: Prosecutor Interview, 1995).”

The reason this issue is complicated resides within the role of the caseworker. Part of their duty is to “...initiate appropriate legal proceedings (CIP Report 2005, pg.27).” The prosecutor's rely on the caseworkers to furnish them with case specific information. Without the information, the prosecutor and judge would have no case. This simple connection illustrates that the roles of the child abuse and neglect courtroom workgroup combine to form a symbiotic relationship.

The major emphasis of the courtroom workgroup is negotiating the formal Court process 
including the hierarchical power structure and making the system function in ways that are more expedient. The relationship between the prosecutor and the caseworkers is one piece of the puzzle. Another piece is the relationship or reliance that judges have on DHHR. In interviews the judges say they relied on caseworker reports in order to make "reasonable efforts" policy determinations. All three workgroups specify that judges rely heavily on the reports DHHR supplies.

When the judges were asked, "What do you think is the impact of the determination of reasonable efforts? Why (CIP: Judge Interview, 2005)?” The judges explained that “reasonable efforts” policy impact relates to DHHR's funding and serves as an evaluation tool. One respondent from the original assessment (in 1995) said, "It keeps the Department on their toes.” This response suggests that the Department is not doing their job and needs to be motivated in some fashion. This reflects a dominant attitude towards DHHR. In this statement the judge is evaluating caseworkers and expressing the underlying statement that the department needs to be pushed. The push that judges referred to appears to have taken the form of public comments. Public admonishment in courtroom workgroups secures the status order within the group and ensures a continuation of the child abuse and neglect process. By making a statement of disapproval the judge reminds the caseworker of their group status and reliance on the court.

This appears to be the case in "reasonable efforts" policy determinations. DHHR is the scapegoat, because they are directly linked to the funding that comes from "reasonable effort" policy determinations. So long as the court (judge and prosecutor) consider their role in "reasonable efforts" policy determinations to be entering an order stating that "reasonable efforts” policy were made they can use this policy as a power equalizer. Both the judges and prosecutors have more administrative authority than an individual caseworker does however the 
caseworker has the full emphasis of the entire department and the ability to seek an appeal. This creates the possibility that the Department could supersede the authority of the other two members of the courtroom workgroup. In the same way that a youngest sibling might go to its grandparents about something (say money to buy a toy), it wants after its older sibling and parents have said no.

This issue surfaced when one of the 2005 responding judges made the statement "This provides checks and balances with the DHHR. Also, it affects eligibility for funding (CIP: Judge Interview, 2005).” Previously we spoke about the balance of power within the courtroom workgroup and then one of the respondents echoed that discussion. The status of the caseworker is not equal to the status associated with the judges and prosecutors even though in this type of court preceding the caseworkers are responsible for the presentation and maintenance of the case.

If this were a criminal court the DHHR caseworker would be taking the role of plaintiff in each child abuse and neglect case. This assigns a certain amount of ownership by the caseworker regarding the occurrence (legal action including the investigation of the alleged abuse) and according to "reasonable efforts", an order must be submitted that states that the Court in conjunction with DHHR did everything within reason before removing a child from its home (See Figure: 1, Appendix A). With all of these elements circulating and feeding into the courtroom workgroup’s own perpetuating cycle it is no wonder that policy’s like "reasonable efforts” policy have such a profound effect on caseworker's perceived role in the West Virginia child abuse and neglect courtroom workgroup structure. 


\section{Chapter 7: Conclusions \& Recommendations}

\section{Conclusion}

West Virginia's low compliance rate for child abuse and neglect cases over the last decade has been analyzed by members of the child abuse and neglect courtroom workgroup. They have made advances in training and software but they continue to overlook the dynamics that divide actual practice from the ideology of "reasonable efforts" policy and the courts overriding goals. Within this divide are the different roles of the courtroom workgroup members, their ownership or part in the "reasonable efforts" policy process and their ability to reward or sanction the other courtroom workgroup members.

My analysis of the 2005 and 1995 open-ended interview responses shows strains between the judges, prosecutors, and caseworkers which often times were voiced through comments directed in a defensive manner. One of courtroom workgroups greatest assets is its ability to share the decision making processes, however this advantage has a potentially damaging repercussion. By sharing decision making through informal concurrent planning and formal hearing processes there is the chance that, if "reasonable efforts" is not found, one of the workgroup members will be used as a scapegoat.

When decision making is shared no professional group has complete ownership of a policy or procedure; however, if other workgroup members are only loosely connected to the child abuse and neglect process, then they can rationally say that it is not their responsibility. We have seen such claims lodged by the judges and prosecutors. The judges make the formal rulings with focus on the five broad procedural stages in the child abuse and neglect process. 
The judge sits on a macro-level in an oversight position for the courtroom workgroup. He/she does not deal with the case management negotiations that make up the case management process constantly operating between the formal hearings. This distances judges from personal practices and responsibility for “reasonable efforts” policy determination past the judicial hearings.

While the prosecutor is lodged within the court, the prosecutor also acts as an intermediary between the legal system and the DHHR caseworkers. In abuse and neglect they constitute the process that allows the caseworker to practice their role in the formal legal proceedings and thus grants or invests the neglect/abuse case with legal relevance before the judiciary. The prosecutors focus is on the formal proceedings and the informal concurrent negotiations of services. This places the prosecutor in a median position between legal and civil actions. The divided/pivotal role of the prosecutor allows them the ability to detach from ownership of "reasonable efforts" policy because their role in the court proceeding is only to present the case as they are presented the material.

This places the caseworker in a situation that is critical to "making the case" in court but also essential to constituting the case as a process for achieving "family unification" yet the caseworker is likely at the bottom of the status and role hierarchy. This position is further compounded by the direct affect that a "reasonable efforts" policy determination has for DHHR. The role of the caseworker in relation to child abuse and neglect proceedings cements the caseworker’s responsibility for “reasonable efforts” policy. The caseworker is directly responsible for the gathering of facts, is the one who makes accusations of abuse or neglect, the service coordinator, and service provider. The caseworkers manage the actual details of the entire child abuse and neglect case from start to finish, removal to reunification/permanent placement. 
With this understanding of the roles and objectives of courtroom workgroup members the situation appears cut and dry. The caseworkers are attached to "reasonable efforts" policy through role and funding so it is reasonable that this policy serves an evaluation function. The problem is that "reasonable efforts" policy is dependent on courtroom workgroup members. It can not be determined based solely on the caseworker's prior efforts or the courts determination with no evidence. "Reasonable efforts" policy is defined with the court in conjunction with the department, making both equally responsible. The ideology of the policy and the goal of the West Virginia child abuse and neglect code state that DHHR and the court must attempt to preserve families and the safety of the child.

These policies and their ability to be operationalized must rely on the judges, prosecutors, and caseworkers to balance their roles and balance their exchanges while ensuring the dockets progression. The hierarchy structure of control in the court (i.e., the process is formally declared to be judge directed) gives the most knowledgeable/informed workgroup members the lesser power over the dealings with other workgroup members. Added to structural hierarchy ideally and actually the courtroom workgroup must make "reasonable efforts" findings within 60 days of the petition being filed.

All of these factors became expressed in the responses that the judges, prosecutors, and caseworkers made when asked about "reasonable efforts" policy. The responses reflected a complex interactive organization that negotiated itself around the legal process, policy practices, and the state's idea of a successful child abuse and neglect case disposition. At first, what appeared to be name-calling, between workgroup members is now reframed and has given rise to "safe" expressions of strain from all three workgroup professions. The expressions; however, only appear safe within the confines of the courtroom workgroup organization model. When 
those sentiments are made and applied outside of the courtroom workgroup (where policy makers and researchers can see them) they become areas of weakness between policy ideals and practice. It is at this locale that past recommendations for the child abuse and neglect system have been made.

In this way the responses from the CIP assessments act as a window into the interactions amidst the courtroom workgroup professionals, policy ideals, and case management practices. This is not to say that adding the concept of the courtroom workgroup to the confines of case management will equal the ideals inherent in policy; although, to date this is how they have been interpreted based on past recommendations. This does however illustrate where policy ideals, practice, and the interactions between courtroom workgroup members overlap. This new area of imbricating concepts and constructs embodies the West Virginia child abuse and neglect system from all levels. These concepts encapsulate the individual professional's interactions, organization policy, and all of the humanitarian ideals associated with the concept of child abuse and neglect courts.

\section{Limitations}

The information from this study is intended to provide insight into the interactions that transform principle and policy ideals into viable practices. Understanding this as an institutional process may benefit child abuse and neglect courts in their attempt to expedite the process and reach Federal compliance rates. This study is intended as a tool to guide future research and to aid policy initiators in understanding how policy can affect the practice of a courtroom workgroup.

This research can provide more cooperation, or at least benefit a collaborative process 
that will enable the courtroom workgroup members to better serve the safety and unity of children and their families. The courtroom workgroup’s new understanding of their situation will allow them to work together more efficiently and on a more open basis. Their open communication will help head off problems that might have cost the court and families months. Orientation of the courtroom workgroup members to the roles that the other workgroup members fill may be advantageous for more successful adjudications. This will lessen the appearance of scapegoating and improve opinions to facilitate case management. The scope of the interactions is relative to "reasonable efforts" policy; however, the interaction situations that arose between workgroups could very easily be relevant to other courtroom workgroup practices.

\section{Recommendations}

In light of the findings, a series of improvements are directed at the CIP structured questionnaires. These questionnaires could prove more useful if they asked more consistent questions and were not formatted with separate sections that is do not appear in all of the interviewed parties questionnaires. An important section that was missing from the caseworker's structure interview was a section inquiring about past experience. The judges and prosecutors had sections devoted to this subject but the caseworker's interview did not.

Another element of the CIP's research was the use of attorneys as interviewers. If the interviews had been conducted by someone outside the courtroom workgroup it is possible that respondents would have felt more comfortable speaking about their role in the child abuse and neglect court. The presence of attorneys might have caused respondents to be less forth coming if they perceived their responses reaching the ears of other courtroom workgroup members.

Apart from the recommendations referring to the data collection process furnishing 
courtroom workgroup members with a seminar that exposes the various pressures attached to child abuse and neglect cases would be beneficial. A sensitization training not for the act of child abuse or dealing with the victims but for understanding the policies and the stresses that the administrative policies create once enacted. This type of training would reinforce their own professional roles and explain the roles of the other courtroom workgroup members.

\section{Future Research}

The CIP reports contain many sections and aspects of child abuse and neglect courts that have not been researched. More in depth research on the workgroup's interactions could drastically improve the State's child abuse and neglect process; especially, in regards to the institutionalized hierarchy that has been briefly discussed. The data gathered by the CIP and the SRC can be used to further basic understanding in the child abuse and neglect system in West Virginia. This is an area that in the past has been relatively unattended. Focus groups and new interviews with the courtroom workgroup members might shed fresh light on the interactions between the workgroup, policy ideals, and practice. My research is not an open and shut case, it is opening the door for future research to explore the structural depths of the child abuse and neglect court system.

Before we can claim to understand how the judicial system works it is imperative that we first understand the workgroups that perpetuate the system. This can be done through studying their interactions and policies within all of the judicial courts, civil and criminal alike. Research such as this and that of other modern researchers can begin the long process of conceptualizing the dynamics that cause courtroom organizations such as, the child abuse and neglect process to falter. 


\section{Figure: 1 Appendix A}

"The Stucture of W.VA. DHMR Caseworker Perceived Role in Child Abuse and Neglect Circuit Courts Through "Reasonable Efforts "Policy."

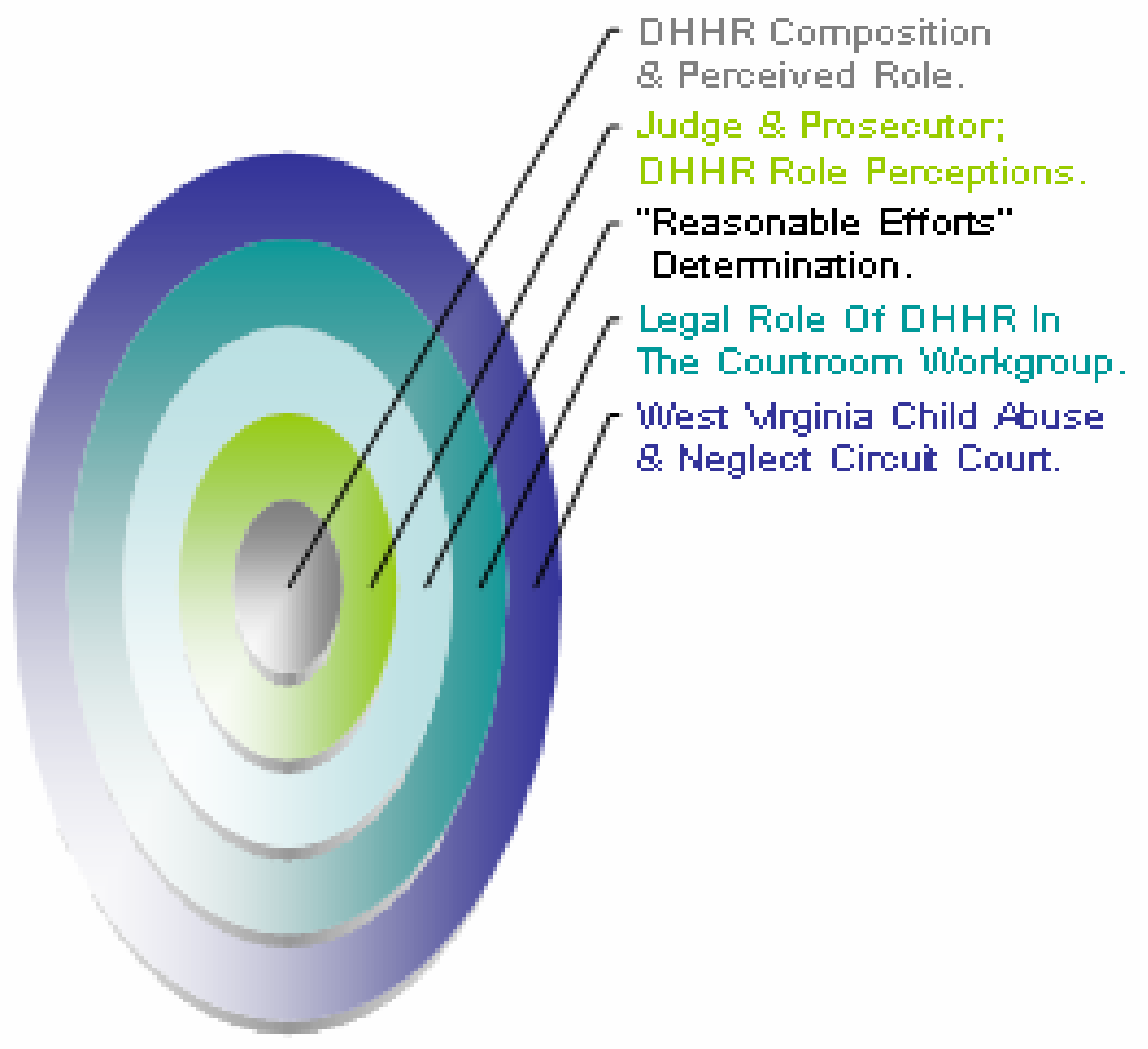




\section{Appendix B:}

\section{TITLE IV-E ELIGIBILITY FOSTER CARE: COURT RELATED STANDARDS}

Title IV-E of the Social Security Act (SSA) sets forth standards for federal payments for foster care and adoption assistance (sections 470-479a of the SSA). Included within these standards are requirements that directly rely on court activity. The failure to comply with these standards can result in the loss of federal funding for a limited period of time or for the duration of the foster care placement. This document outlines federal Title IV-E eligibility standards that involve the court and addresses compliance issues relating to those standards.

\section{A. FEDERAL REMOVAL OF CHILD}

Federal Standard: The child must have been removed from his or her home as a result of either a court order or a voluntary placement agreement. Under federal Title IV-E standards, a voluntary placement agreement is valid for 180 days after placement, after which, the basis for the child being in foster care must be a court order that finds that placement would be in the best interests of the child.

Reference: Section 472(a) (1) of the SSA.

Impact of Non-Compliance: Federal funding under Title IV-E is not available until the court order is issued or a voluntary placement agreement is executed. Title IV-E is not available where a child is placed pursuant to a voluntary placement and a court determination of best interests has not been made within 180 days of placement.

Compliance Issues: For Title IV-E purposes, a voluntary transfer of care and custody pursuant to section 384-a of the Social Services (SSL) is a voluntary placement agreement. If a child is placed into foster care pursuant to a section 384 surrender, the child is not eligible for Title IV-E foster care until a section 358-a court order approving the placement is granted.

- When the basis for the child being cared for is either a section 1021 removal with consent or a section 1024 removal without consent, the child is not eligible for Title IV-E until a court order (section 1027/1028/1055) is issued granting the social services district care and custody of the child and adequately addressing the issues of contrary to the welfare, best interests and reasonable efforts as noted below.

- Absent a court determination addressing contrary to the welfare, best interests, Title IV-E eligibility for a child voluntarily placed terminates 180 days after placement. This problem arises when a timely section 358-a order is not pursued and obtained

\section{B. LEGAL AUTHORITY}

Federal Standard: The child must be in the care and placement of the State (OCFS) or other public agency (local department of social services). The commissioner of social services or OCFS must have care and custody or custody and guardianship of the child either pursuant to a court order or a voluntary placement agreement (local departments only).

Reference: Section 472(a)(2) of the SSA.

Impact of Non-Compliance: Federal Title IV-E funding is not available until the local commissioner or OCFS assumes legal custody of the child. 


\section{Compliance Issue:}

- The most common problem with legal authority is where a time-limited court order granting custody is not extended on a timely basis. When that takes place, legal authority lapses and Tile IV-E funding must cease at the end of the month the order lapses.

- Legal authority may resume with a subsequent court order on the first day of the month the order was issued. However, for Title IV-E purposes, legal authority may not be retroactively applied through a nunc pro tunc court order. Nunc pro trunc orders are not recognized or acceptable to the federal Title IV-E oversight agency.

\section{BEST INTERESTS}

Federal Standard: A child's removal from his or her home must have been the result of a judicial determination to the effect that continuation in the home would be contrary to the welfare of the child or that placement would be in the best interests of the child (contrary to welfare/best interests). The judicial determination regarding contrary to the welfare/ best interests must be explicitly documented in the initial court order sanctioning removal and must be made on a case-by-case basis.

References: Section 472(a)(1) of the SSA; 45 CFR 1356.21(c) and 45 CFR 1356.21(d)

Impact of Non-Compliance: Federal regulation, 45 CFR 1356.21(c) provides that the failure to make a timely and adequate court finding of contrary to welfare/best interests pertaining to removal results in the loss of federal Title IV-E funding for the duration of the foster care placement.

Compliance Issues:

- The most common problem was where the initial court order sanctioning removal of the child fails to reflect a case specific finding regarding contrary to welfare/best interests. For example, the order concludes that continuation in the home would be contrary to the best interests of the child but fails to specify the facts and/or documents upon which the court is basing its conclusion.

- Federal funding is not available where the court indicates that it would not be contrary to the welfare of the child to remain in his or her home, while in the same order, the court places the child into foster care.

\section{REASONABLE EFFORTS - REMOVAL}

Federal Standard: When a child is removed from his or her home, a case specific judicial determination whether reasonable efforts were made to prevent removal or that reasonable efforts were not required must be made within 60 days of the removal of the child from his or her home.

References: Section 471(a)(15) of the SSA; 45 CFR 1356.21(b)(1) and 45 CFR 1356.21(d)

Impact of Non-Compliance: Federal regulation, 45 CFR 1356.21(c), provides that the failure to make a timely and adequate finding of reasonable efforts results in the loss of federal Title IV$\mathrm{E}$ funding for the duration of the foster care placement.

Compliance Issues:

- The court order fails to adequately document reasonable efforts by not reflecting a case specific finding. For example, the court concludes that reasonable efforts were made but the order does not specify the facts and/or documents upon which the court is basing its conclusion.

- The court order reflects a finding that reasonable efforts were not made but it would have 
otherwise been appropriate for the court to have found that the lack of efforts was in fact reasonable.

- The court fails to make a timely determination of reasonable efforts. This occurs where a child is removed on an emergency basis and the court order sanctioning removal is not issued until more than 60 days from the date the child was removed from his or her home. In such a situation, the adequacy of the court finding addressing reasonable efforts is not relevant because of the lack of timeliness. Timeliness is an issue in two particular categories of cases. One is when the child is removed on an emergency basis pursuant to either section 1021 or 1024 of the FCA and a section 1027 or 1028 hearing is not held within 60 days of removal. The other situation is where the court in a case under either an Article 3 or 7 of the FCA places a child into detention and fails to adequately address the issue of reasonable efforts (and/or best interests).

\section{E. REASONABLE EFFORTS - FINALIZE PERMANENCY PLAN}

Federal Standard: The initial permanency hearing leading to a judicial determination of reasonable efforts to finalize the child's permanency plan, including where the plan is return to parent, must be held within 12 months of the entry of the child into foster care (a child is considered to have entered foster care on the earlier of the fact finding of abuse or neglect or the date that is 60 days after the removal of the child from his or her home). Subsequent permanency hearings in which the issue of reasonable efforts to finalize the child's permanency plan must be explicitly addressed in the court order, must be held every 12 months from the preceding permanency hearing.

References: Section 471(a)(15) of the SSA; 45 CFR 1356.21(b)(2) and 45 CFR 1356.21(d)

Impact of Non-Compliance: Federal regulation, 45 CFR 1356.21(b)(2) provides that if a reasonable efforts determination is not made on a timely basis, the foster care case remains ineligible for federal Title IV-E funding until such a judicial determination is made.

Compliance Issues:

- Some cases reflect the failure of the agency to file the petition for a permanency hearing on a timely basis thus precluding a timely court determination from not being made.

- Some cases reflect a timely filing of the petition for a permanency hearing but for the hearing is not held in a timely basis.

- Some cases failed to include a court order with a case specific finding or contain a conclusion that reasonable efforts were made but do not specify upon what facts and/or documents the court is basing its conclusion.

- Some cases conclude that reasonable efforts were not made because of a change in permanency plan when the court could have appropriately concluded that reasonable efforts were made to pursue the revised permanency plan.

- In some cases where the time period for an extension and permanency hearing were due, a temporary order was granted extending placement and legal authority. However, if the order fails to address reasonable efforts towards permanency, the case is rendered ineligible for federal Title IV-E funding until an adequate reasonable efforts order is issued.

\section{F. PLACEMENT WITH SPECIFIC FOSTER CARE PROVIDER}

Federal Standard: Title IV-E reimbursement is not available when a court orders a placement with a specific foster care provider.

References: 45 CFR 1356.21(g)(3) 
Impact of Non-Compliance: Title IV-E funding not available for the period of time the child is cared for in the court directed placement. Compliance Issues: - In some proceedings, the court will direct the child to be placed in a particular foster care facility or foster home (see sections 353.3(2), 756(a)(ii) and 1017 of the Family Court Act). Input of the social services district, the county or OCFS must have been presented to the court for the placement to be eligible for Title IV-E funding, even if the recommendation is not accepted by the court. 


\section{References}

Berg, Bruce L. 2004. Qualitative Research Methods: For the Social Sciences.5ed. Boston, MA: Pearson Education, Inc.

Child Welfare Information Gateway, July 15, 2006. http://www.childwelfare.gov/can/index.cfm.

Eisenstein, James and Herbert Jacob. 1977. Felony Justice: An Organizational Analysis of Criminal Courts. Boston, MA. Brown and company (Inc).

Emerson, Robert. 1969. Judging delinquents; context and process in juvenile court. Chicago, Aldine Pub. Co.

Harden, Mark. 1990. “Ten Years Later: Implementation of Public Law 96-272 by the Courts,” in the Adoption Assistance and Child Welfare Act of 1980, ed. North American Council on Adoptable Children (St.Paul, Minn.: North American Council on Adoptable Children, 1990).

Johnson, William A. Jr., Richard P. Rettig, Gregory M. Scott and Stephen M. Garrison. 2004. The Sociology Student Writer's Manual. 4ed. Upper Saddle River, NJ: Pearson Prentice Hall.

Knepper, Paul E. and Shannon M. Barton. 1997. The Effect of Courtroom Dynamics on Child Maltreatment Proceedings. Social Science Review 6:288-308.

Strauss, Anselm L. 2003. Qualitative Analysis: For Social Scientists. San Francisco, CA: Cambridge University Press.

W.V. Child Welfare Committee. 2000. West Virginia State Child Welfare Code Chapter 49. Rules of Procedure for Child Abuse and Neglect Proceedings.

W.V. Court Administrative Office. 1995. Court Administrative Office. Pending Cases Age/County Summary Report.

W.V. Court Improvement Oversight Board. Court Performance in Child Abuse and Neglect Cases: Re-Assessment Open-ended Questions. Mailed Survey Questionnaire Responses.

W. V. Supreme Court. 2005. Court Improvement Oversight Board: Child Abuse and Neglect Report. Court Performance In Child Abuse and Neglect Cases: ReAssessment Report and Recommendations. pp. i-90. 